\title{
Design of dual inhibitors of soluble epoxide hydrolase and LTA hydrolase
}

Kerstin Hiesinger, ${ }^{a}$ Annika Schott, ${ }^{\text {a }}$ Jan S. Kramer, ${ }^{a}$ René Blöcher, ${ }^{a}$ Finja Witt, ${ }^{b}$ Sandra

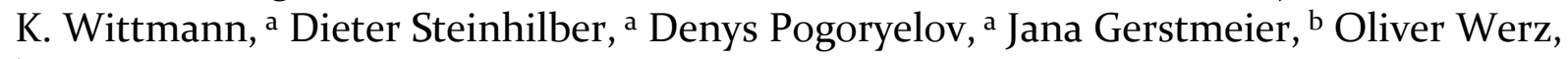
$\mathrm{b}$ and Ewgenij Proschak ${ }^{\mathrm{a}}$

${ }^{a}$ Institute of Pharmaceutical Chemistry, Goethe University Frankfurt, Max-von-Laue-Strasse 9, 60438 Frankfurt, Germany

b Department of Pharmaceutical/Medicinal Chemistry, Institute of Pharmacy, Friedrich-Schiller-University Jena, Philosophenweg 14, 07743 Jena, Germany.

\section{Contents of SI:}

Chemistry materials and general procedures

Analytical data of the synthesized compounds

$\mathrm{LTA}_{4} \mathrm{H}$ expression and purification

$\mathrm{LTA}_{4} \mathrm{H}$ activity assay with 7-amido-4-methylcoumarine

SEH expression and purification

SEH-H activity assay with PHOME

water solubility assay

Co-crystallization of 9 with the C-terminal domain of SEH

Proposed binding mode of 13 in the binding site of $\mathrm{LTA}_{4} \mathrm{H}$

Cellular assays in macrophages

References

Chemistry materials and general procedures

All used solvents and chemicals were purchased from Sigma-Aldrich Chemie GmbH (Munich, Germany), Acros Organics (Geel, Belgium), Alfa-Aesar GmbH \& Co KG (Karlsruhe, Germany), TCI Europe (Zwijndrecht, Belgium), Fluorochem (Derbyshire, England) and Apollo Scientific Ltd. (Manchester, England) and used without further purification. Analytical TLC (thin layer chromatography) was performed with TLC plates F254 from Merck (KGaA, Darmstadt, Germany) and visualized with ultraviolet light ( 254 and $365 \mathrm{~nm}$ ). Column chromatography was performed with technical grade solvent mixtures specified in the corresponding experiment with either Fluka silica gel 60 (230-400 mesh ASTM) or an Intelliflash 310 system from Varian Medical Systems Deutschland GmbH (Darmstadt, Germany) with silica columns from Varian (particle size $50 \mu \mathrm{m}) .{ }^{1} \mathrm{H}-\mathrm{NMR}$ spectra were recorded on a Bruker DPX 250 (250 MHz), AV300 (300 MHz), AV400 (400 MHz) or AV500 (500 MHz) 
spectrometer (Bruker, Karlsruhe, Germany). ${ }^{1} \mathrm{H}-\mathrm{NMR}$ data are reported in ppm downfield relative to tetramethylsilane: internal reference non-deuterated solvent. The multiplicities are b, broad; $s$, singlet; $\mathrm{d}$, doublet; $\mathrm{dd}$, double doublet; $\mathrm{t}$, triplet; $\mathrm{m}$, multiplet and the approximate coupling constant $(\mathrm{J})$ are reported in hertz $(\mathrm{Hz}) .{ }^{13} \mathrm{C}-\mathrm{NMR}$ spectra were recorded on a Bruker AV300 (75 MHz) or AV500 (125 $\mathrm{MHz}$ ) spectrometer (Bruker, Karlsruhe, Germany). HPLC analysis were performed by a LCMS 2020 from Shimadzu (Duisburg, Germany) under the use of a column from Phenomenex Luna 10 $\mu$ C18(2) $100 \mathrm{~A}$ $(250 \times 4.60 \mathrm{~mm})$ for analytical purposes and a Luna $10 \mu \mathrm{C} 18(2)(250 \times 21.20 \mathrm{~mm})$ column from Phenomenex LTD Deutschland (Aschaffenburg, Germany) for preparative purposes. Condition were as followed: acetonitrile/0.1\% aqueous formic acid eluent at $1 \mathrm{~mL} / \mathrm{min}$ (Scout column) or $21 \mathrm{~mL} / \mathrm{min}$ (semi-preparative) flow rate at room temperature. UV absorption was monitored at 254 and $280 \mathrm{~nm}$. Purity of all compounds were determined by following methods: method A: Gradient of $30 \%$ to $90 \%$ acetonitrile within $10 \mathrm{~min}, 90 \%$ acetonitrile were hold for another $10 \mathrm{~min}$. method B: $5 \%$ acetonitrile for $5 \mathrm{~min}$, afterwards a gradient of $5 \%$ to $90 \%$ acetonitrile within $10 \mathrm{~min}, 90 \%$ acetonitrile were hold for another $10 \mathrm{~min}$. ESI-MS was performed on a VG Platform II from Fisons Instruments (Glasgow, UK) or on a LCMS-2020 from Shimadzu (Duisburg, Germany). MALDI-HRMS was performed on a MALDI LTQ Orbitrap XL instrument (Thermo Scientific, USA). Purity of all final compounds were $90 \%$ or higher determined by HPLC.

\section{Procedure A}

Under inert conditions 2.0 eq thionyl chloride were diluted in $5 \mathrm{~mL}$ dry chloroform and a cat. amount of DMF. 1.0 eq 4-phenoxyphenylacetic acid was added and the solution stirred $3 \mathrm{~h}$ under reflux conditions. After removing all solvents under reduced pressure, the solid was solved in $5 \mathrm{~mL}$ dry chloroform. A solution of 1.5 eq DIPEA and 1.0 eq amine was added and the approach stirred overnight at room temperature. The reaction mixture was washed with $2 \mathrm{M}$ aqueous hydrochloric acid (1x), with $1 \mathrm{M}$ aqueous sodium hydroxide solution (1x), with dest. water (3x) and brine (1x). After drying over $\mathrm{MgSO}_{4}$ and filtration the solvent was evaporated under reduced pressure. Flash chromatography (hexane:ethyl acetate $2: 1$ to $100 \%$ ethyl acetate) yielded a yellow - white solid.

\section{Procedure B}

The acid derivative was dissolved in $15 \mathrm{~mL} \mathrm{DCM}$ and $1 \mathrm{~mL}$ DMF. To the solution 1.0 eq EDC.HCl and 1.0 eq $\mathrm{HOBt} \cdot \mathrm{H}_{2} \mathrm{O}$ were added and the approach stirred for 30 minutes at room temperature. Additionally, the corresponding 1.0 eq amine and $1.0-2.0$ eq DIPEA were added and the reaction stirred overnight. The mixture was washed with $2 \mathrm{M}$ aqueous hydrochloric acid ( $1 \mathrm{x}$ ), with $1 \mathrm{M}$ aqueous sodium hydroxide solution (1x), with dest. water (3x) and brine (1x). After drying over $\mathrm{MgSO}_{4}$ and filtration the solvent was removed under reduced pressure. Flash chromatography (hexane:ethyl acetate $2: 1$ to $100 \%$ ethyl acetate) yielded a yellow - white solid

\section{Procedure $\mathbf{C}$}

1.0 eq phenyl isothiocyanate derivative, 1.1 eq of the phenol derivative, 0.05 eq Cul, 0.1 eq phenanthroline and 2.0 eq $\mathrm{K}_{2} \mathrm{CO}_{3}$ were suspended in $7 \mathrm{~mL}$ 1,4-dioxane. The approach was heated to $90{ }^{\circ} \mathrm{C}$ for 3 days. The suspension was filtered over a Celite ${ }^{\circledR}$ pad with ethyl acetate and the solvent was evaporated. The residue was purified via flash chromatography (hexane:ethyl acetate 2:1, 1:1 to 100\% ethyl acetate). A solid was obtained.

\section{Analytical data of the synthesized compounds}

2-(4-phenoxyphenyl)- $\mathrm{N}$-(4-(trifluoromethoxy)phenethyl)acetamide (3): procedure B: educts: 2-(4phenoxyphenyl)acetic acid, 2-(4-(trifluoromethoxy)phenyl)ethanamine; $\mathrm{C}_{23} \mathrm{H}_{20} \mathrm{~F}_{3} \mathrm{NO}_{3} ; \quad \mathrm{MW}$ : $415.41 \mathrm{~g} / \mathrm{mol}$; yield: $96 \mathrm{mg}, 0.23 \mathrm{mmol}, 77 \%$; ${ }^{1} \mathrm{H}-\mathrm{NMR}:\left(500.2 \mathrm{MHz}, \mathrm{CDCl}_{3}\right): \delta=7.40-7.32\left(\mathrm{~m}, 2 \mathrm{H}, \mathrm{H}_{\mathrm{ar}}\right)$, 7.15-7.07 (m, 7H, $\left.\mathrm{H}_{\mathrm{ar}}\right), 7.03-7.00\left(\mathrm{~m}, 2 \mathrm{H}, \mathrm{H}_{\mathrm{ar}}\right), 6.96-6.93\left(\mathrm{~m}, 2 \mathrm{H}, \mathrm{H}_{\mathrm{ar}}\right), 5.40(\mathrm{bs}, 1 \mathrm{H}, \mathrm{NH}), 3.50\left(\mathrm{~s}, 2 \mathrm{H}, \mathrm{CH}_{2}\right)$, $3.47\left(\mathrm{q}, 2 \mathrm{H}, 3^{3} \mathrm{HH}_{\mathrm{HH}}=6.6 \mathrm{~Hz}, \mathrm{CH}_{2}\right), 2.76\left(\mathrm{t}, 2 \mathrm{H},{ }^{3} \mathrm{~J}_{\mathrm{HH}}=6.9 \mathrm{~Hz}, \mathrm{CH}_{2}\right)$ ppm; ${ }^{13} \mathrm{C}-\mathrm{NMR}:\left(125.8 \mathrm{MHz}, \mathrm{CDCl}_{3}\right): \delta=$ 
$171.1,157.0,156.9,148.0$ (q), 137.6, 130.9, 130.1, 130.0, 129.4, 123.8, 121.3, 119.3, 119.1, 43.2, 40.7, $35.0 \mathrm{ppm} ; \mathrm{t}_{\mathrm{R}}: 12.33 \mathrm{~min}$ (method A), purity: 99\%, HRMS: measured: 416.14639, calculated: 416.14680 , $\Delta \mathrm{m}: 1.0 \mathrm{ppm},\left[\mathrm{M}+\mathrm{H}^{+}\right]$.

2-(4-phenoxyphenyl)- $\mathrm{N}$-(4-(trifluoromethyl)phenethyl)acetamide (5): procedure $\mathrm{B}$ : educts: 2-(4phenoxyphenyl)acetic acid, 2-(4-(trifluoromethyl)phenyl)ethanamine; $\mathrm{C}_{23} \mathrm{H}_{20} \mathrm{~F}_{3} \mathrm{NO}_{2} ; \quad \mathrm{MW}$ : $399.41 \mathrm{~g} / \mathrm{mol}$; yield: $105 \mathrm{mg}, 0.26 \mathrm{mmol}, 88 \%$; ${ }^{1} \mathrm{H}-\mathrm{NMR}:\left(500.2 \mathrm{MHz}, \mathrm{CDCl}_{3}\right): \delta=7.51(\mathrm{~d}, 2 \mathrm{H}$, $\left.{ }^{3} \mathrm{~J}_{\mathrm{HH}}=8.0 \mathrm{~Hz}, \mathrm{H}_{\mathrm{ar}}\right), 7.37-7.33\left(\mathrm{~m}, 2 \mathrm{H}, \mathrm{H}_{\mathrm{ar}}\right), 7.19\left(\mathrm{~d}, 2 \mathrm{H},{ }^{3} \mathrm{JHH}_{\mathrm{HH}}=8.0 \mathrm{~Hz}, \mathrm{H}_{\mathrm{ar}}\right), 7.15-7.11\left(\mathrm{~m}, 3 \mathrm{H}, \mathrm{H}_{\mathrm{ar}}\right), 7.03-7.00$ $\left(\mathrm{m}, 2 \mathrm{H}, \mathrm{H}_{\mathrm{ar}}\right), 6.96-6.93\left(\mathrm{~m}, 2 \mathrm{H}, \mathrm{H}_{\mathrm{ar}}\right), 5.40(\mathrm{bs}, 1 \mathrm{H}, \mathrm{NH}), 3.51-3.47\left(\mathrm{~m}, 4 \mathrm{H}, \mathrm{CH}_{2}\right), 2.82\left(\mathrm{t}, 2 \mathrm{H}, 3_{\mathrm{HH}}=6.9 \mathrm{~Hz}\right.$, $\mathrm{CH}_{2}$ ) ppm; ${ }^{13} \mathrm{C}-\mathrm{NMR}:\left(125.8 \mathrm{MHz}, \mathrm{CDCl}_{3}\right): \delta=171.2,157.0,156.9,143.0$ (d), 130.9, 130.0, 129.3, 129.2, $128.9,125.6$ (d), 125.4, 123.8, 123.2, 119.3, 119.1, 43.2, 40.5, 35.5 ppm; $t_{R}: 12.06 \min (\operatorname{method} A)$, purity: 99\%, HRMS: measured: 400.15157 , calculated: $400.15189, \Delta \mathrm{m}: 0.8 \mathrm{ppm},\left[\mathrm{M}+\mathrm{H}^{+}\right]$.

$\mathbf{N}$-(4-fluorophenethyl)-2-(4-phenoxyphenyl)acetamide (6): procedure $\quad A$; educts: 2-(4phenoxyphenyl)acetic acid, 2-(4-fluorophenyl)ethanamine; $\mathrm{C}_{22} \mathrm{H}_{20} \mathrm{FNO}_{2} ; \mathrm{MW}: 349.40 \mathrm{~g} / \mathrm{mol}$; Yield: $79 \mathrm{mg}, 0.23 \mathrm{mmol}, 31 \%$; ${ }^{1} \mathrm{H}-\mathrm{NMR}:\left(250.0 \mathrm{MHz}, \mathrm{CDCl}_{3}\right): \delta=7.39-7.33\left(\mathrm{~m}, 2 \mathrm{H}, \mathrm{H}_{\mathrm{ar}}\right), 7.14\left(\mathrm{~m}, 3 \mathrm{H}, \mathrm{H}_{\mathrm{ar}}\right)$, 7.10-6.90 (m, 8H, $\left.\mathrm{H}_{\mathrm{ar}}\right), 5.34(\mathrm{bs}, 1 \mathrm{H}, \mathrm{NH}), 3.47-3.42\left(\mathrm{~m}, 4 \mathrm{H}, \mathrm{CH}_{2}\right), 2.72\left(\mathrm{t}, 2 \mathrm{H},{ }^{3} \mathrm{~J}_{\mathrm{HH}}=5.0 \mathrm{~Hz}, \mathrm{CH}_{2}\right) \mathrm{ppm}$; ${ }^{13}$ C-NMR: $\left(75.4 \mathrm{MHz}, \mathrm{CDCl}_{3}\right.$ ): $\delta=171.1,157.0$ (d), 130.9, 130.3, 130.2, 130.0, 129.5, 123.7, 119.2 (d), 115.7, 115.4, 43.2, 40.8, $34.9 \mathrm{ppm}$; $\mathrm{t}_{\mathrm{R}}$ : $11.19 \mathrm{~min}$ (method A), purity: 99\%, HRMS: measured: 350.15563, calculated: $350.15508, \Delta \mathrm{m}: 1.4 \mathrm{ppm},\left[\mathrm{M}+\mathrm{H}^{+}\right]$.

$\mathbf{N}$-(4-chlorophenethyl)-2-(4-phenoxyphenyl)acetamide (7): procedure $\quad A$; $\quad$ educts: 2-(4phenoxyphenyl)acetic acid, 2-(4-chlorophenyl)ethanamine; $\mathrm{C}_{22} \mathrm{H}_{20} \mathrm{ClNO}{ }_{2} ; \mathrm{MW}: 365.85 \mathrm{~g} / \mathrm{mol}$; Yield: $60 \mathrm{mg}, 0.16 \mathrm{mmol}, 31 \%$; ${ }^{1} \mathrm{H}-\mathrm{NMR}:\left(250.0 \mathrm{MHz}, \mathrm{CDCl}_{3}\right): \delta=7.39-7.33\left(\mathrm{~m}, 2 \mathrm{H}, \mathrm{H}_{\mathrm{ar}}\right), 7.24-7.20\left(\mathrm{~m}, 2 \mathrm{H}, \mathrm{H}_{\mathrm{ar}}\right)$, 7.17-7.11 (m, $\left.3 \mathrm{H}, \mathrm{H}_{\mathrm{ar}}\right), 7.03-6.94\left(\mathrm{~m}, 6 \mathrm{H}, \mathrm{H}_{\mathrm{ar}}\right), 5.34(\mathrm{bs}, 1 \mathrm{H}, \mathrm{NH}), 3.50\left(\mathrm{~s}, 2 \mathrm{H}, \mathrm{CH}_{2}\right), 3.48-3,43\left(\mathrm{~m}, 2 \mathrm{H}, \mathrm{CH}_{2}\right)$, $2.72\left(\mathrm{t}, 2 \mathrm{H},{ }^{3} \mathrm{H}_{\mathrm{HH}}=7.1 \mathrm{~Hz}, \mathrm{CH}_{2}\right)$ ppm; ${ }^{13} \mathrm{C}-\mathrm{NMR}:\left(75.4 \mathrm{MHz}, \mathrm{CDCl}_{3}\right): \delta=170.0,156.8,138.5,131.6,130.7$, $130.6,130.5,129.8,128.7,123.6,119.2,119.0,43.0,40.5,34.9 ; \mathrm{t}_{\mathrm{R}}: 11.87 \min (\operatorname{method} \mathrm{A})$, purity: $93 \%$, HRMS: measured: 366.1255 , calculated: $366.1258, \Delta \mathrm{m}: 0.8 \mathrm{ppm},\left[\mathrm{M}+\mathrm{H}^{+}\right]$.

$\mathbf{N}$-(4-methylphenethyl)-2-(4-phenoxyphenyl)acetamide $\quad$ (8): procedure $\quad A$; educts: 2-(4phenoxyphenyl)acetic acid, 2-( $p$-tolyl)ethanamine; $\mathrm{C}_{23} \mathrm{H}_{23} \mathrm{NO}_{2} ; \mathrm{MW}: 345.43 \mathrm{~g} / \mathrm{mol}$; Yield: $80 \mathrm{mg}$, $0.23 \mathrm{mmol}, 21 \%$; ${ }^{1} \mathrm{H}-\mathrm{NMR}:\left(400.0 \mathrm{MHz}, \mathrm{CDCl}_{3}\right): \delta=7.38-7.33\left(\mathrm{~m}, 2 \mathrm{H}, \mathrm{H}_{\mathrm{ar}}\right), 7.15-7.11\left(\mathrm{~m}, 3 \mathrm{H}, \mathrm{H}_{\mathrm{ar}}\right), 7.07-$ $7.00\left(\mathrm{~m}, 4 \mathrm{H}, \mathrm{H}_{\mathrm{ar}}\right), 6.96-6.92\left(\mathrm{~m}, 4 \mathrm{H}, \mathrm{H}_{\mathrm{ar}}\right), 5.36(\mathrm{bs}, 1 \mathrm{H}, \mathrm{NH}), 3.50\left(\mathrm{~s}, 2 \mathrm{H}, \mathrm{CH}_{2}\right), 3.49-3.44\left(\mathrm{~m}, 2 \mathrm{H}, \mathrm{CH}_{2}\right)$, $2.71\left(\mathrm{t}, 2 \mathrm{H},{ }^{3}{ }_{\mathrm{HH}}=7.0 \mathrm{~Hz}, \mathrm{CH}_{2}\right), 2.31\left(\mathrm{~s}, 3 \mathrm{H}, \mathrm{CH}_{3}\right)$ ppm; ${ }^{13} \mathrm{C}-\mathrm{NMR}:\left(75.4 \mathrm{MHz}, \mathrm{CDCl}_{3}\right): \delta=170.8,156.9$, $156.6,136.0,135.5,130.8,129.8,129.5,129.3,128.6,123.5,119.1,119.0,43.0,40.7,35.0,21.0 ; t_{R}$ 11,34 min (method A), purity: 99\%; HRMS: measured: 346.18079, calculated: 346.18016, $\Delta \mathrm{m}: 1.7$ ppm, $\left[\mathrm{M}+\mathrm{H}^{+}\right]$.

\section{2-(4-fluorophenyl)- $\mathrm{N}$-(4-phenoxybenzyl)ethanamine (9):}

Under an inert atmosphere $0.20 \mathrm{~g}$ (1.01 mmol, $1.0 \mathrm{eq})$ 4-phenoxybenzaldehyde and $0.17 \mathrm{~g}(1.21 \mathrm{mmol}$, 1.2 eq) 2-(4-fluorophenyl)ethanamine were dissolved in $3 \mathrm{~mL}$ abs. 1,2-dichloroethane. The approach stirred for $4 \mathrm{~h}$ and a suspension was formed. $0.26 \mathrm{~g}(1.21 \mathrm{mmol}, 1.2 \mathrm{eq})$ sodium triacetoxyhydroborate were added and stirred $16 \mathrm{~h}$. After removal of the solvent the residue was diluted with ethyl acetate and washed with saturated sodium bisulfite solution. The formed precipitate was removed, the organic phase was dried over $\mathrm{MgSO}_{4}$ and filtered. The solvent was evaporated and flash chromatography (100\% ethyl acetate) yielded a colorless oil.

$\mathrm{C}_{21} \mathrm{H}_{20} \mathrm{FNO}$; MW: $321.39 \mathrm{~g} / \mathrm{mol}$; yield: $65 \mathrm{mg}, 0.20 \mathrm{mmol}, 20 \%$; ${ }^{1} \mathrm{H}-\mathrm{NMR}:\left(300.1 \mathrm{MHz}, \mathrm{CD}_{3} \mathrm{OD}\right): 7.36-$ $7.26\left(\mathrm{~m}, 4 \mathrm{H}, \mathrm{H}_{\mathrm{ar}}\right), 7.23-7.17\left(\mathrm{~m}, 2 \mathrm{H}, \mathrm{H}_{\mathrm{ar}}\right), 7.12-7.06\left(\mathrm{~m}, 1 \mathrm{H}, \mathrm{H}_{\mathrm{ar}}\right), 7.03-6.91\left(\mathrm{~m}, 6 \mathrm{H}, \mathrm{H}_{\mathrm{ar}}\right), 3.74\left(\mathrm{~s}, 2 \mathrm{H}, \mathrm{CH}_{2}\right)$, 2.80 (s, 4H, CH${ }_{2}$ ) ppm; ${ }^{13} \mathrm{C}-\mathrm{NMR}:\left(75.4 \mathrm{MHz}, \mathrm{CD}_{3} \mathrm{OD}\right): \delta=164.6,161.3,158.8,157.9,137.0$ (d), 135.5, $311.1,130.8,124.3,119.8,116.2,116.9,53.7,51.4,35.8 ; t_{R}: 10.68 \min$ (method $B$ ), purity: $98 \%$, HRMS: measured: 322.16039 , calculated: $322.16017, \Delta \mathrm{m}: 0.68 \mathrm{ppm},\left[\mathrm{M}+\mathrm{H}^{+}\right]$. 
$\mathbf{N}$-(4-fluorophenethyl)-3-(4-hydroxyphenyl)propanamide (precursor of 10): Under an argon atmosphere at $0{ }^{\circ} \mathrm{C} 0.18 \mathrm{~g}(0.71 \mathrm{mmol}, 1.0 \mathrm{eq})$ iodine were dissolved in $10 \mathrm{~mL}$ abs. DCM and $0.19 \mathrm{~g}$ ( $0.71 \mathrm{mmol}, 1.0 \mathrm{eq}) \mathrm{PPh}_{3}$ were added. After $15 \mathrm{~min}$ the lilac color disappeared and $0.99 \mathrm{~g}(0.71 \mathrm{mmol}$, 1.0 eq) 2-(4-fluorophenyl)ethanamine, dissolved in $5 \mathrm{~mL}$ abs. DCM, were added portionwise. $0.10 \mathrm{~g}$ ( $0.60 \mathrm{mmol}, 0.9$ eq) 3-(4-hydroxyphenyl)propanoic acid and $0.2 \mathrm{~mL}(1.20 \mathrm{mmol}, 1.7$ eq) triethylamine were added and the approach stirred for $19 \mathrm{~h}$ at room temperature. The solution was concentrated and purified via column chromatography (hexane: ethyl acetate 1:4).

$\mathrm{C}_{17} \mathrm{H}_{18} \mathrm{FNO}_{2}$; MW: $287.33 \mathrm{~g} / \mathrm{mol}$; yield: $0.05 \mathrm{~g}, 0.17 \mathrm{mmol}, 24 \%$; ${ }^{1} \mathrm{H}-\mathrm{NMR}:(250.1 \mathrm{MHz}, \mathrm{DMSO}): 9.11$ (s, $1 \mathrm{H}, \mathrm{OH}), 7.82\left(\mathrm{t}, 1 \mathrm{H}, 3^{3} \mathrm{HH}_{\mathrm{H}}=5.6 \mathrm{~Hz}, \mathrm{NH}\right), 7.19-7.10\left(\mathrm{~m}, 4 \mathrm{H}, \mathrm{H}_{\mathrm{ar}}\right), 6.97-6.94\left(\mathrm{~m}, 2 \mathrm{H}, \mathrm{H}_{\mathrm{ar}}\right), 6.67-6.62(\mathrm{~m}, 2 \mathrm{H}$, $\left.\mathrm{H}_{\mathrm{ar}}\right)$, 3.26-3.18 $\left(\mathrm{m}, 2 \mathrm{H}, \mathrm{CH}_{2}\right), 2.69-2.62\left(\mathrm{~m}, 4 \mathrm{H}, \mathrm{CH}_{2}\right), 2.30-2.2 .24\left(\mathrm{~m}, 2 \mathrm{H}, \mathrm{CH}_{2}\right)$ ppm; LRMS: measured: 287.95, calculated: $287.13,\left[\mathrm{M}+\mathrm{H}^{+}\right]$.

\section{$\mathbf{N}$-(4-fluorophenethyl)-3-(4-(pyridin-4-ylmethoxy)phenyl)propanamide (10):}

$43 \mathrm{mg}(0.15 \mathrm{mmol}, 1.0 \mathrm{eq}) \mathrm{N}$-(4-fluorophenethyl)-3-(4-hydroxyphenyl)propanamide were dissolved in $5 \mathrm{~mL}$ THF and $18 \mathrm{mg}\left(0.45 \mathrm{mmol}, 3.0 \mathrm{eq}, 60 \%\right.$ oil dispersion) $\mathrm{NaH}$ were added at $0{ }^{\circ} \mathrm{C}$. The suspension stirred $30 \mathrm{~min}$ at $0{ }^{\circ} \mathrm{C} .42 \mathrm{mg}(0.17 \mathrm{mmol}, 1.1 \mathrm{eq}) 4$-(bromomethyl)pyridine hydrobromide were added portionwise and $1 \mathrm{~mL}$ dest. water was added. The reaction stirred for $18 \mathrm{~h}$ at room temperature and was quenched with $1 \mathrm{~N}$ aqueous hydrochloric acid. The product was extracted with ethyl acetate three times and the combined organic phases were washed with brine. After drying over $\mathrm{MgSO}_{4}$ and filtration the solvent was removed under reduced pressure. The crude product was purified via preparative HPLC (method: gradient of 10\% acetonitrile to $90 \%$ within $14 \mathrm{~min}, 90 \%$ acetonitrile were hold for 3 minutes).

$\mathrm{C}_{23} \mathrm{H}_{23} \mathrm{FN}_{2} \mathrm{O}_{2} ; \mathrm{MW}: 378.40 \mathrm{~g} / \mathrm{mol}$; yield: $65 \mathrm{mg} ; 0.20 \mathrm{mmol} ; 20 \%$; ${ }^{1} \mathrm{H}-\mathrm{NMR}$ : (250.1 MHz, DMSO): 8.55 $\left(\mathrm{dd}, 2 \mathrm{H},{ }^{3} \mathrm{JHH}_{\mathrm{HH}}=6.0 \mathrm{~Hz},{ }^{4} \mathrm{~J}_{\mathrm{HH}}=1.5 \mathrm{~Hz}, \mathrm{H}_{\mathrm{ar}}\right), 7.86\left(\mathrm{t}, 1 \mathrm{H},{ }^{3} \mathrm{~J}_{\mathrm{HH}}=6.7 \mathrm{~Hz}, \mathrm{NH}\right), 7.42-7.40\left(\mathrm{~m}, 2 \mathrm{H}, \mathrm{H}_{\mathrm{ar}}\right), 7.02-7.04$ $\left(\mathrm{m}, 6 \mathrm{H}, \mathrm{H}_{\mathrm{ar}}\right), 6.94-6.88\left(\mathrm{~m}, 2 \mathrm{H}, \mathrm{H}_{\mathrm{ar}}\right), 5.14\left(\mathrm{~s}, 2 \mathrm{H}, \mathrm{CH}_{2}\right), 3.26-3.18\left(\mathrm{~m}, 2 \mathrm{H}, \mathrm{CH}_{2}\right), 2.75-2.61\left(\mathrm{~m}, 4 \mathrm{H}, \mathrm{CH}_{2}\right)$,

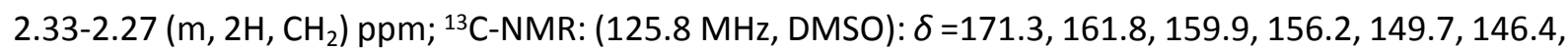
135.7 (d), 133.9, 130.4, 129.3, 121.8, 115.0, 114.8, 114.6, 67.4, 372, 34.3, 30.2 ppm; $\mathrm{t}_{\mathrm{R}}: 7.2 \mathrm{~min}$ (method B), purity: 97\%, HRMS: measured: 379.18171 , calculated: $379.18163, \Delta \mathrm{m}: 0.21 \mathrm{ppm},\left[\mathrm{M}+\mathrm{H}^{+}\right]$.

$\mathbf{N}$-(4-fluorophenethyl)-2-(4-hydroxyphenyl)acetamide (precursor of 13): procedure B: educts: 2-(4hydroxyphenyl)-acetic acid, 2-(4-fluorophenyl)ethanamine; $\mathrm{C}_{16} \mathrm{H}_{16} \mathrm{FNO}_{2} ; \mathrm{MW}: 273.30$; yield: $1.47 \mathrm{~g}$, $5.38 \mathrm{mmol}, 40 \%$; ${ }^{1} \mathrm{H}-\mathrm{NMR}:(400.1 \mathrm{MHz}, \mathrm{DMSO}): \delta=9.20(\mathrm{~s}, 1 \mathrm{H}, \mathrm{OH}), 7.92\left(\mathrm{t}, 1 \mathrm{H},{ }^{3} \mathrm{H}_{\mathrm{HH}}=5.4 \mathrm{~Hz}, \mathrm{NH}\right), 7.20-$ $7.15\left(\mathrm{~m}, 2 \mathrm{H}, \mathrm{H}_{\mathrm{ar}}\right), 7.09-7.03\left(\mathrm{~m}, 2 \mathrm{H}, \mathrm{H}_{\mathrm{ar}}\right), 7.00-6.97\left(\mathrm{~m}, 2 \mathrm{H}, \mathrm{H}_{\mathrm{ar}}\right), 6.68-6.64\left(\mathrm{~m}, 2 \mathrm{H}, \mathrm{H}_{\mathrm{ar}}\right), 3.27-3.22(\mathrm{~m}, 4 \mathrm{H}$, $\left.\mathrm{CH}_{2}\right), 2.67\left(\mathrm{t}, 2 \mathrm{H},{ }^{3} \mathrm{~J}_{\mathrm{HH}}=7.2 \mathrm{~Hz}, \mathrm{CH}_{2}\right)$ ppm; LRMS: measured: 274.00 , calculated: $273.12\left[\mathrm{M}+\mathrm{H}^{+}\right]$.

2-(2-fluoro-4-hydroxyphenyl)- $\mathrm{N}$-(4-fluorophenethyl)acetamide (precursor of 14-18): procedure $\mathrm{B}$; educts: 2-(2-fluoro-4-hydroxyphenyl)acetic acid, 2-(4-fluorophenyl)ethanamine; $\mathrm{C}_{16} \mathrm{H}_{15} \mathrm{~F}_{2} \mathrm{NO}_{2} ; \mathrm{MW}$ : $291.29 \mathrm{~g} / \mathrm{mol}$; yield: $256 \mathrm{mg}, 0.88 \mathrm{mmol}, 91 \%$; ${ }^{1} \mathrm{H}-\mathrm{NMR}:\left(250.1 \mathrm{MHz}, \mathrm{CDCl}_{3}\right): \delta=8.58(\mathrm{~s}, 1 \mathrm{H}, \mathrm{OH}), 7.05-$ $\left.6.89\left(\mathrm{~m}, 5 \mathrm{H}, \mathrm{H}_{\mathrm{ar}}\right), 6.60-6.55\left(\mathrm{~m}, 2 \mathrm{H}, \mathrm{H}_{\mathrm{ar}}\right), 5.52\left(\mathrm{t}, 1 \mathrm{H},{ }^{3}\right)_{\mathrm{HH}}=5.7 \mathrm{~Hz}, \mathrm{NH}\right), 3.48-3.40\left(\mathrm{~m}, 4 \mathrm{H}, \mathrm{CH}_{2}\right), 2.71(\mathrm{t}$, $2 \mathrm{H},{ }^{3} \mathrm{~J}_{\mathrm{HH}}=6.9 \mathrm{~Hz}, \mathrm{CH}_{2}$ ) ppm; LRMS: measured: 289.80 , calculated: $291.11,\left[\mathrm{M}-\mathrm{H}^{+}\right]$.

2-(2-fluoro-4-hydroxyphenyl)-N-(2-fluorophenethyl)acetamide (precursor of 19): procedure $\mathrm{B}$; educts: 2-(2-fluoro-4-hydroxyphenyl)acetic acid, 2-(2-fluorophenyl)ethanamine; $\mathrm{C}_{16} \mathrm{H}_{15} \mathrm{~F}_{2} \mathrm{NO}_{2} ; \mathrm{MW}$ : $291.29 \mathrm{~g} / \mathrm{mol}$; yield: $359 \mathrm{mg}, 1.23 \mathrm{mmol}, 84 \%$; ${ }^{1} \mathrm{H}-\mathrm{NMR}:\left(250.1 \mathrm{MHz}, \mathrm{CDCl}_{3}\right): \delta=7.94$ (bs, $\left.1 \mathrm{H}, \mathrm{OH}\right), 7.22-$ $7.14\left(\mathrm{~m}, 1 \mathrm{H}, \mathrm{H}_{\mathrm{ar}}\right), 7.12-6.93\left(\mathrm{~m}, 4 \mathrm{H}, \mathrm{H}_{\mathrm{ar}}\right), 6.56-6.49\left(\mathrm{~m}, 2 \mathrm{H}, \mathrm{H}_{\mathrm{ar}}\right), 5.76\left(\mathrm{t}, 1 \mathrm{H},{ }^{3} \mathrm{~J}_{\mathrm{HH}}=5.6 \mathrm{~Hz}, \mathrm{NH}\right), 3.54-3.46$ $\left(\mathrm{m}, 4 \mathrm{H}, \mathrm{CH}_{2}\right), 2.82\left(\mathrm{t}, 2 \mathrm{H},{ }^{3}{ }_{\mathrm{HH}}=7.0 \mathrm{~Hz}, \mathrm{CH}_{2}\right)$ ppm; LRMS: measured: 292.19, calculated: $291.11,\left[\mathrm{M}+\mathrm{H}^{+}\right]$.

2-(2-fluoro-4-hydroxyphenyl)-N-(3-fluorophenethyl)acetamide (precursor of 20): procedure $B$, educts: 2-(2-fluoro-4-hydroxyphenyl)acetic acid, 2-(3-fluorophenyl)ethanamine; $\mathrm{C}_{16} \mathrm{H}_{15} \mathrm{~F}_{2} \mathrm{NO}_{2} ; \mathrm{MW}$ : $291.29 \mathrm{~g} / \mathrm{mol}$; yield: $370 \mathrm{mg}, 1.27 \mathrm{mmol}, 86 \%$; ${ }^{1} \mathrm{H}-\mathrm{NMR}$ : $\left(300.0 \mathrm{MHz}, \mathrm{CDCl}_{3}\right): \delta=7.98$ (bs, $1 \mathrm{H}, \mathrm{OH}$ ), $7.25-$ 
$7.17\left(\mathrm{~m}, 1 \mathrm{H}, \mathrm{H}_{\mathrm{ar}}\right), 7.00-6.79\left(\mathrm{~m}, 4 \mathrm{H}, \mathrm{H}_{\mathrm{ar}}\right), 6.58-6.52\left(\mathrm{~m}, 2 \mathrm{H}, \mathrm{H}_{\mathrm{ar}}\right), 5.76\left(\mathrm{t}, 1 \mathrm{H},{ }^{3} \mathrm{~J}_{\mathrm{HH}}=5.7 \mathrm{~Hz}, \mathrm{NH}\right), 3.52-3.46$ $\left(\mathrm{m}, 4 \mathrm{H}, \mathrm{CH}_{2}\right), 2.76\left(\mathrm{t}, 2 \mathrm{H},{ }^{3} \mathrm{~J}_{\mathrm{HH}}=6.1 \mathrm{~Hz}, \mathrm{CH}_{2}\right)$ ppm; LRMS: measured: 292.19 , calculated: $291.11,\left[\mathrm{M}+\mathrm{H}^{+}\right]$.

methyl 4-((2-(2-fluoro-4-hydroxyphenyl)acetamido)methyl)benzoate (precursor of 21): procedure B; educts: 2-(2-fluoro-4-hydroxyphenyl)acetic acid, methyl 4-(aminomethyl)benzoate hydrochloride; $\mathrm{C}_{17} \mathrm{H}_{16} \mathrm{FNO}_{4}$; MW: $317.31 \mathrm{~g} / \mathrm{mol}$; yield: $202 \mathrm{mg}, 0.64 \mathrm{mmol}, 43 \%$; ${ }^{1} \mathrm{H}-\mathrm{NMR}:(400.1 \mathrm{MHz}, \mathrm{DMSO}): \delta=9.67$ (bs, $1 \mathrm{H}, \mathrm{OH}), 8.50\left(\mathrm{t}, 1 \mathrm{H},{ }^{3} \mathrm{~J}_{\mathrm{HH}}=8.8 \mathrm{~Hz}, \mathrm{NH}\right), 7.91-7.89\left(\mathrm{~m}, 2 \mathrm{H}, \mathrm{H}_{\mathrm{ar}}\right), 7.36\left(\mathrm{~d}, 2 \mathrm{H},{ }^{3} \mathrm{~J}_{\mathrm{HH}}=6.1 \mathrm{~Hz}, \mathrm{H}_{\mathrm{ar}}\right), 7.09$ $\left(\mathrm{t}, 1 \mathrm{H},{ }^{3} \mathrm{~J}_{\mathrm{HH}}=8.6 \mathrm{~Hz}, \mathrm{H}_{\mathrm{ar}}\right), 6.55-6.49\left(\mathrm{~m}, 2 \mathrm{H}, \mathrm{H}_{\mathrm{ar}}\right), 4.35\left(\mathrm{~d}, 2 \mathrm{H},{ }^{3} \mathrm{~J}_{\mathrm{HH}}=6.0 \mathrm{~Hz}, \mathrm{CH}_{2}\right), 3.84\left(\mathrm{~s}, 3 \mathrm{H}, \mathrm{CH}_{3}\right), 3.41$

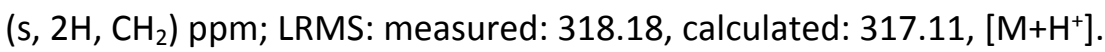

$\mathbf{N}$-((6-fluoro-1H-indol-3-yl)methyl)-2-(2-fluoro-4-hydroxyphenyl)acetamide (precursor of 22): procedure B; educts: 2-(2-fluoro-4-hydroxyphenyl)acetic acid, (6-fluoro-1H-indol-3-yl)methanamine; $\mathrm{C}_{17} \mathrm{H}_{14} \mathrm{~F}_{2} \mathrm{~N}_{2} \mathrm{O}_{2}$; MW: $316.30 \mathrm{~g} / \mathrm{mol}$; yield: $344 \mathrm{mg}, 1.09 \mathrm{mmol}, 82 \%$; ${ }^{1} \mathrm{H}-\mathrm{NMR}$ : (400.1 MHz, DMSO): $\delta=$ $10.97(\mathrm{~s}, 1 \mathrm{H}, \mathrm{NH}$ indole), 9.66 (bs, $1 \mathrm{H}, \mathrm{OH}), 8.22\left(\mathrm{t}, 1 \mathrm{H},{ }^{3} \mathrm{JHH}_{\mathrm{H}}=10.7 \mathrm{~Hz}, \mathrm{NH}\right), 7.56-7.48\left(\mathrm{~m}, 1 \mathrm{H}, \mathrm{H}_{\mathrm{ar}}\right), 7.23$ $\left(\mathrm{s}, 1 \mathrm{H}, \mathrm{H}_{\mathrm{ar}}\right), 7.14-7.06\left(\mathrm{~m}, 2 \mathrm{H}, \mathrm{H}_{\mathrm{ar}}\right), 6.86-6.80\left(\mathrm{~m}, 1 \mathrm{H}, \mathrm{H}_{\mathrm{ar}}\right), 6.54-6.49\left(\mathrm{~m}, 2 \mathrm{H}, \mathrm{H}_{\mathrm{ar}}\right), 4.38(\mathrm{~d}, 2 \mathrm{H}$, $\left.{ }^{3} \mathrm{~J}_{\mathrm{HH}}=6.7 \mathrm{~Hz}, \mathrm{CH}_{2}\right), 3.34\left(\mathrm{~s}, 2 \mathrm{H}, \mathrm{CH}_{2}\right)$ ppm, LRMS: measured: 339.04, calculated: 339.09, [M+Na+].

2-(4-(benzo[d]thiazol-2-yloxy)phenyl)- $\mathbf{N}$-(4-fluorophenethyl)acetamide (13): procedure C: educts: $\mathrm{N}$ (4-fluorophenethyl)-2-(4-hydroxyphenyl)acetamide, 1-bromo-3-isothiocyanatobenzene;

$\mathrm{C}_{23} \mathrm{H}_{19} \mathrm{FN}_{2} \mathrm{O}_{2} \mathrm{~S}$; MW: $406.47 \mathrm{~g} / \mathrm{mol}$; yield: $350 \mathrm{mg}, 0.86 \mathrm{mmol}, 86 \%$; ${ }^{1} \mathrm{H}-\mathrm{NMR}:(500.2 \mathrm{MHz}, \mathrm{DMSO}): \delta=$ $8.16\left(\mathrm{t}, 1 \mathrm{H},{ }^{3} \mathrm{~J}_{\mathrm{HH}}=5.5 \mathrm{~Hz}, \mathrm{NH}\right), 7.92\left(\mathrm{dd}, 1 \mathrm{H},{ }^{3} J_{\mathrm{HH}}=8.0 \mathrm{~Hz},{ }^{4} J_{\mathrm{HH}}=0.8 \mathrm{~Hz}, \mathrm{H}_{\mathrm{ar}}\right), 7.69\left(\mathrm{~d}, 1 \mathrm{H},{ }^{3} J_{\mathrm{HH}}=8.0 \mathrm{~Hz}\right.$, $\left.\mathrm{H}_{\mathrm{ar}}\right), 7.44-7.40\left(\mathrm{~m}, 1 \mathrm{H}, \mathrm{H}_{\mathrm{ar}}\right), 7.37-7.31\left(\mathrm{~m}, 5 \mathrm{H}, \mathrm{H}_{\mathrm{ar}}\right), 7.22-7.18\left(\mathrm{~m}, 2 \mathrm{H}, \mathrm{H}_{\mathrm{ar}}\right), 7.11-7.07\left(\mathrm{~m}, 2 \mathrm{H}, \mathrm{H}_{\mathrm{ar}}\right), 3.43(\mathrm{~s}$, $\left.2 \mathrm{H}, \mathrm{CH}_{2}\right), 3.29\left(\mathrm{q}, 2 \mathrm{H},{ }^{3} \mathrm{JHH}_{\mathrm{HH}}=6.7 \mathrm{~Hz}, \mathrm{CH}_{2}\right), 2.71\left(\mathrm{t}, 2 \mathrm{H},{ }^{3} \mathrm{~J}_{\mathrm{HH}}=7.1 \mathrm{~Hz}, \mathrm{CH}_{2}\right)$ ppm; ${ }^{13} \mathrm{C}-\mathrm{NMR}:(125.8 \mathrm{MHz}$, DMSO): $\delta=172.0,169.8,161.8,159.9,152.9,148.6,135.6$ (d), 134.9, 131.8, 130.7, 130.5, 130.4, 126.5, $124.2,122.2,121.2,120.7,115.0,114.9,41.7,40.3,34.1$ ppm; $t_{R}: 11.35 \min (\operatorname{method} A)$, purity: $98 \%$, HRMS: measured: 429.10447, calculated: 429.10435, $\Delta \mathrm{m}: 0.3 \mathrm{ppm},\left[\mathrm{M}+\mathrm{Na}^{+}\right]$.

2-(4-(benzo[d]thiazol-2-yloxy)-2-fluorophenyl)- $\mathrm{N}$-(4-fluorophenethyl)acetamide (14). procedure $\mathrm{C}$; educts: 2-(2-fluoro-4-hydroxyphenyl)- $\mathrm{N}$-(4-fluorophenethyl)acetamide, 1-bromo-2-isothiocyanatobenzene; $\mathrm{C}_{23} \mathrm{H}_{18} \mathrm{~F}_{2} \mathrm{~N}_{2} \mathrm{O}_{2} \mathrm{~S}$; MW: $424.46 \mathrm{~g} / \mathrm{mol}$; yield: $65 \mathrm{mg}, 0.15 \mathrm{mmol}, 22 \%$; ${ }^{1} \mathrm{H}-\mathrm{NMR}:(250.1 \mathrm{MHz}$, $\left.\mathrm{CDCl}_{3}\right)$ : 7.77-7.70 (m, $\left.2 \mathrm{H}, \mathrm{H}_{\mathrm{ar}}\right), 7.45-7.27\left(\mathrm{~m}, 3 \mathrm{H}, \mathrm{H}_{\mathrm{ar}}\right), 7.23-7.15\left(\mathrm{~m}, 2 \mathrm{H}, \mathrm{H}_{\mathrm{ar}}\right), 7.08-6.94\left(\mathrm{~m}, 4 \mathrm{H}, \mathrm{H}_{\mathrm{ar}}\right), 5.50$ (s, $1 \mathrm{H}, \mathrm{NH}), 3.54-3.44\left(\mathrm{~m}, 4 \mathrm{H}, \mathrm{CH}_{2}\right), 2.77\left(\mathrm{t}, 2 \mathrm{H},{ }^{3} \mathrm{~J}_{\mathrm{HH}}=7.4 \mathrm{~Hz}, \mathrm{CH}_{2}\right) \mathrm{ppm} ;{ }^{13} \mathrm{C}-\mathrm{NMR}:\left(75.4 \mathrm{MHz}, \mathrm{CDCl}_{3}\right): \delta$ $=169.3,160.0,154.4,148.7,134.3$ (d), 130.2, 130.0, 126.4, 124.5, 121.9, 121.4, 119.9, 119.6, 116.6 (d), 115.6, 115.2, 108.8, 108.4, 41.0, 36.7, 34.7 ppm; $t_{R}$ : 11.81 min (method A), purity: 96\%, HRMS: measured: 425.11298, calculated: 425.11287, $\Delta \mathrm{m}: 0.21 \mathrm{ppm},\left[\mathrm{M}+\mathrm{H}^{+}\right]$.

2-(2-fluoro-4-((6-fluorobenzo[d]thiazol-2-yl)oxy)phenyl)-N-(4-fluorophenethyl)acetamide

(15): procedure $\mathrm{C}$; educts: 2-(2-fluoro-4-hydroxyphenyl)- $\mathrm{N}$-(4-fluorophenethyl)acetamide, 2-bromo-4fluoro-1-isothiocyanatobenzene; $\mathrm{C}_{23} \mathrm{H}_{17} \mathrm{~F}_{3} \mathrm{~N}_{2} \mathrm{O}_{2} \mathrm{~S}$; MW: $442.45 \mathrm{~g} / \mathrm{mol}$; yield: $334 \mathrm{mg}, 0.76 \mathrm{mmol}, 97 \%$; ${ }^{1} \mathrm{H}-\mathrm{NMR}:(400.1 \mathrm{MHz}, \mathrm{DMSO}): 8.17\left(\mathrm{t}, 1 \mathrm{H},{ }^{3} J_{\mathrm{HH}}=5.5 \mathrm{~Hz}, \mathrm{NH}\right), 7.90\left(\mathrm{dd}, 1 \mathrm{H},{ }^{3} J_{\mathrm{HH}}=8.7 \mathrm{~Hz},{ }^{4} J_{\mathrm{HH}}=2.7 \mathrm{~Hz}\right.$, $\left.\mathrm{H}_{\mathrm{ar}}\right), 7.76-7.73\left(\mathrm{~m}, 1 \mathrm{H}, \mathrm{H}_{\mathrm{ar}}\right), 7.44-7.38\left(\mathrm{~m}, 2 \mathrm{H}, \mathrm{H}_{\mathrm{ar}}\right), 7.32-7.21\left(\mathrm{~m}, 4 \mathrm{H}, \mathrm{H}_{\mathrm{ar}}\right), 7.13-7.08\left(\mathrm{~m}, 2 \mathrm{H}, \mathrm{H}_{\mathrm{ar}}\right), 3.49(\mathrm{~s}$, $\left.2 \mathrm{H}, \mathrm{CH}_{2}\right), 3.30-3.27\left(\mathrm{~m}, 2 \mathrm{H}, \mathrm{CH}_{2}\right), 2.72\left(2 \mathrm{H}, \mathrm{t},{ }^{3} \mathrm{H}_{\mathrm{HH}}=7.9 \mathrm{~Hz}, \mathrm{CH}_{2}\right)$ ppm; ${ }^{13} \mathrm{C}-\mathrm{NMR}:(75.4 \mathrm{MHz}, \mathrm{DMSO}): \delta=$ $168.7,145.1,135.5$ (d), 133.0, 132.9, 132.6 (d), 130.4 (d), 122.5, 122.4, 121.8, 121.7, 116.6, 115.0, 114.8. 114.7, 114.4, 109.1, 108.9, 108.7, 108.5, 40.7, 34.9, 34.1 ppm; $t_{R}: 11.3$ min (method A), purity: 99\%, HRMS: measured: 443.10342, calculated: 443.10356, $\Delta \mathrm{m}: 0.32 \mathrm{ppm},\left[\mathrm{M}+\mathrm{H}^{+}\right]$.

2-(2-fluoro-4-((6-(trifluoromethyl)benzo[d] thiazol-2-yl)oxy)phenyl)- $\mathrm{N}$-(4-fluorophenethyl)acetamide (16); procedure C; educts: 2-(2-fluoro-4-hydroxyphenyl)- $N$-(4-fluorophenethyl)acetamide, 2bromo-1-isothiocyanato-4-(trifluoromethyl)benzene; $\mathrm{C}_{24} \mathrm{H}_{17} \mathrm{~F}_{5} \mathrm{~N}_{2} \mathrm{O}_{2} \mathrm{~S} ; \mathrm{MW}: 492.46 \mathrm{~g} / \mathrm{mol}$; yield: $179 \mathrm{mg}, 0.36 \mathrm{mmol}, 58 \%$; ${ }^{1} \mathrm{H}-\mathrm{NMR}$ : (300.1 MHz, DSMO): 8.48 (d, $\left.1 \mathrm{H},{ }^{4} J_{\mathrm{HH}}=1.2 \mathrm{~Hz}, \mathrm{H}_{\mathrm{ar}}\right), 8.18(\mathrm{t}, 1 \mathrm{H}$, $\left.{ }^{3} J_{\mathrm{HH}}=5.5 \mathrm{~Hz}, \mathrm{NH}\right), 7.90\left(\mathrm{~d}, 1 \mathrm{H},{ }^{3} J_{\mathrm{HH}}=8.5 \mathrm{~Hz}, \mathrm{H}_{\mathrm{ar}}\right), 7.75\left(\mathrm{dd}, 1 \mathrm{H},{ }^{3} J_{\mathrm{HH}}=8.5 \mathrm{~Hz},{ }^{4} J_{\mathrm{HH}}=1.6 \mathrm{~Hz}, \mathrm{H}_{\mathrm{ar}}\right), 7.48-7.40$ $\left(\mathrm{m}, 2 \mathrm{H}, \mathrm{H}_{\mathrm{ar}}\right), 7.30-7.7 .21\left(\mathrm{~m}, 3 \mathrm{H}, \mathrm{H}_{\mathrm{ar}}\right), 7.13-7.07\left(\mathrm{~m}, 2 \mathrm{H}, \mathrm{H}_{\mathrm{ar}}\right), 3.50\left(\mathrm{~s}, 2 \mathrm{H}, \mathrm{CH}_{2}\right), 3.31-3.29\left(\mathrm{~m}, 2 \mathrm{H}, \mathrm{CH}_{2}\right)$, 
$2.72\left(2 \mathrm{H}, \mathrm{t},{ }^{3} \mathrm{~J}_{\mathrm{HH}}=7.9 \mathrm{~Hz}, \mathrm{CH}_{2}\right) \mathrm{ppm} ;{ }^{13} \mathrm{C}-\mathrm{NMR}:(100.6 \mathrm{MHz}$, DMSO): $\delta=174.4,168.7,153.2,151.3,135.5$, $132.7,132.5,130.4$ (d), 123.4, 122.9, 122.2, 122.0, 121.8, 120.3 (q), 116.7 (d), 115.5, 114.8, 108.9, 108.7, 40.3, 34.9, 34.1 ppm; $t_{R}: 12.0$ min (method A), purity: 97\%, HRMS: measured: 493.099762, calculated: $493.10037, \Delta \mathrm{m}: 1.23 \mathrm{ppm},\left[\mathrm{M}+\mathrm{H}^{+}\right]$.

2-(2-fluoro-4-((5-(trifluoromethyl)benzo[d] thiazol-2-yl)oxy)phenyl)- $\mathrm{N}$-(4-fluorophenethyl)acet-

amide (17): procedure C; educts: 2-(2-fluoro-4-hydroxyphenyl)- $\mathrm{N}$-(4-fluorophenethyl)acetamide, 1bromo-2-isothiocyanato-4-(trifluoromethyl)benzene; $\mathrm{C}_{24} \mathrm{H}_{17} \mathrm{~F}_{5} \mathrm{~N}_{2} \mathrm{O}_{2} \mathrm{~S}$; $\mathrm{MW}: 492.46 \mathrm{~g} / \mathrm{mol}$; yield: $157 \mathrm{mg}, 0.32 \mathrm{mmol}, 48 \%$; ${ }^{1} \mathrm{H}-\mathrm{NMR}:\left(400.1 \mathrm{MHz}, \mathrm{CDCl}_{3}\right): 8.23-8.17\left(\mathrm{~m}, 2 \mathrm{H}, \mathrm{NH}, \mathrm{H}_{\mathrm{ar}}\right), 8.10\left(\mathrm{bs}, 1 \mathrm{H}, \mathrm{H}_{\mathrm{ar}}\right)$, $7.68\left(\mathrm{dd}, 1 \mathrm{H},{ }^{3} \mathrm{~J}_{\mathrm{HH}}=8.4 \mathrm{~Hz},{ }^{4} \mathrm{JHH}_{\mathrm{H}}=1.4 \mathrm{~Hz}, \mathrm{H}_{\mathrm{ar}}\right), 7.48-7.40\left(\mathrm{~m}, 2 \mathrm{H}, \mathrm{H}_{\mathrm{ar}}\right), 7.30-7.21\left(\mathrm{~m}, 3 \mathrm{H}, \mathrm{H}_{\mathrm{ar}}\right), 7.13-7.07$ $\left(\mathrm{m}, 2 \mathrm{H}, \mathrm{H}_{\mathrm{ar}}\right), 3.50\left(\mathrm{~s}, 2 \mathrm{H}, \mathrm{CH}_{2}\right), 3.31-3.28\left(\mathrm{~m}, 2 \mathrm{H}, \mathrm{CH}_{2}\right), 2.78\left(\mathrm{t}, 2 \mathrm{H},{ }^{3} \mathrm{H}_{\mathrm{HH}}=7.2 \mathrm{~Hz}, \mathrm{CH}_{2}\right) \mathrm{ppm} ;{ }^{13} \mathrm{C}-\mathrm{NMR}$ : (100.6 MHz, DSMO): $\delta=173.3,168.7,162.0,161.6,159.6,159.2,153.1,148.4,136.2,135.5,132.7$ (q), $132.5,130.4$ (d), 123.6, 116.7, 115.0, 114.8, 10.9, 108.6, 40.4, 34.9, 34.1 ppm; $\mathrm{t}_{\mathrm{R}}: 12.0 \mathrm{~min}(\operatorname{method} \mathrm{A})$, purity: 96\%, HRMS: measured: 493.09961, calculated: 493.10037, $\Delta \mathrm{m}: 1.54 \mathrm{ppm},\left[\mathrm{M}+\mathrm{H}^{+}\right]$.

2-(2-fluoro-4-((5-fluorobenzo[d]thiazol-2-yl)oxy)phenyl)-N-(4-fluorphenethyl)acetamide

(18): procedure $\mathrm{C}$; educts: 2-(2-fluoro-4-hydroxyphenyl)- $\mathrm{N}$-(4-fluorophenethyl)acetamide, 1-bromo-4fluoro-2-isothiocyanatobenzene; $\mathrm{C}_{23} \mathrm{H}_{17} \mathrm{~F}_{3} \mathrm{~N}_{2} \mathrm{O}_{2} \mathrm{~S}$; $\mathrm{MW}: 442.45 \mathrm{~g} / \mathrm{mol}$; yield: $142 \mathrm{mg}, 0.32 \mathrm{mmol}, 49 \%$; ${ }^{1} \mathrm{H}-\mathrm{NMR}$ : $\left(250.1 \mathrm{MHz}, \mathrm{CDCl}_{3}\right)$ : 7.69-7.65 (m, $\left.1 \mathrm{H}, \mathrm{H}_{\mathrm{ar}}\right), 7.44-7.29\left(\mathrm{~m}, 2 \mathrm{H}, \mathrm{H}_{\mathrm{ar}}\right), 7.22-7.13\left(\mathrm{~m}, 3 \mathrm{H}, \mathrm{H}_{\mathrm{ar}}\right), 7.11-$ $6.93\left(\mathrm{~m}, 4 \mathrm{H}, \mathrm{H}_{\mathrm{ar}}\right), 5.49(\mathrm{bs}, 1 \mathrm{H}, \mathrm{NH}), 3.55\left(\mathrm{~s}, 2 \mathrm{H}, \mathrm{CH}_{2}\right), 3.51-3.47\left(\mathrm{~m}, 2 \mathrm{H}, \mathrm{CH}_{2}\right), 2.77\left(\mathrm{t}, 2 \mathrm{H},{ }^{3}\right)_{\mathrm{HH}}=7.3 \mathrm{~Hz}$, $\mathrm{CH}_{2}$ ) ppm; ${ }^{13} \mathrm{C}$-NMR: $\left(75.4 \mathrm{MHz}, \mathrm{CDCl}_{3}\right): \delta=169.4,154.5,134.4,132.4$ (d), 130.3 (d), 123.0, 122.9, 120.2, 119.9, 116.7 (d), 115.7, 115.5, 115.0, 114.6, 108.9, 108.6, 108.4, 108.3, 108.0, 40.9, 36.6, 34.7 ppm; $t_{R}$ : 11.3 min (method A), purity: 97\%, HRMS: measured: 443.10320, calculated: $443.10356, \Delta \mathrm{m}: 0.81 \mathrm{ppm}$, $\left[\mathrm{M}+\mathrm{H}^{+}\right]$.

2-(4-(benzo[d]thiazol-2-yloxy)-2-fluorophenyl)- $\mathrm{N}$-(2-fluorophenethyl)acetamide (19): procedure C; educts: 2-(2-fluoro-4-hydroxyphenyl)- $N$-(2-fluorophenethyl)acetamide, 1-bromo-2-isothiocyanatobenzene; $\mathrm{C}_{23} \mathrm{H}_{18} \mathrm{~F}_{2} \mathrm{~N}_{2} \mathrm{O}_{2} \mathrm{~S}$; MW: $424.46 \mathrm{~g} / \mathrm{mol}$; yield: $384 \mathrm{mg}, 1.21 \mathrm{mmol}, 98 \%$; ${ }^{1} \mathrm{H}-\mathrm{NMR}$ : $(400.1 \mathrm{MHz}$, DMSO): $8.23\left(\mathrm{t}, 1 \mathrm{H}, 3_{\mathrm{HH}}=5.6 \mathrm{~Hz}, \mathrm{NH}\right), 7.95\left(\mathrm{dd}, 1 \mathrm{H},{ }^{3} \mathrm{JHH}_{\mathrm{HH}}=8.0 \mathrm{~Hz},{ }^{4} J_{\mathrm{HH}}=2.9 \mathrm{~Hz}, \mathrm{H}_{\mathrm{ar}}\right), 7.72(\mathrm{~d}, 1 \mathrm{H}$, $\left.3 J_{\mathrm{HH}}=8.0 \mathrm{~Hz}, \mathrm{H}_{\mathrm{ar}}\right), 7.46-7.24\left(\mathrm{~m}, 7 \mathrm{H}, \mathrm{H}_{\mathrm{ar}}\right), 7.17-7.00\left(\mathrm{~m}, 2 \mathrm{H}, \mathrm{H}_{\mathrm{ar}}\right), 3.50\left(\mathrm{~s}, 2 \mathrm{H}, \mathrm{CH}_{2}\right), 3.31-3.30\left(\mathrm{~m}, 4 \mathrm{H}, \mathrm{CH}_{2}\right)$, $2.78\left(\mathrm{t}, 2 \mathrm{H},{ }^{3}{ }_{\mathrm{HH}}=7.0 \mathrm{~Hz}, \mathrm{CH}_{2}\right)$ ppm; ${ }^{13} \mathrm{C}-\mathrm{NMR}:(100.6 \mathrm{MHz}$, DMSO): $\delta=171.3,168.7,153.4,153.3,148.4$, $131.9,131.2$ (d), 128.3, 128.2, 126.5, 124.3, 122.2, 121.3, 116.6 (d), 115.2, 115.0, 108.7, 108.5, 40.1, 34.8 , $34.6 \mathrm{ppm} ; \mathrm{t}_{\mathrm{R}}: 11.3 \mathrm{~min}$ (method A), purity: 97\%, HRMS: measured: 425.11267, calculated: 425.11298, $\Delta \mathrm{m}: 0.73 \mathrm{ppm},\left[\mathrm{M}+\mathrm{H}^{+}\right]$.

2-(4-(benzo[d]thiazol-2-yloxy)-2-fluorophenyl)- $\mathrm{N}$-(3-fluorophenethyl)acetamide (20): procedure $\mathrm{C}$, educts: 2-(2-fluoro-4-hydroxyphenyl)- $\mathrm{N}$-(3-fluorophenethyl)acetamide, 1-bromo-2-isothiocyanatobenzene; $\mathrm{C}_{23} \mathrm{H}_{18} \mathrm{~F}_{2} \mathrm{~N}_{2} \mathrm{O}_{2} \mathrm{~S}$; MW: $424.46 \mathrm{~g} / \mathrm{mol}$; yield: $228 \mathrm{mg}, 0.54 \mathrm{mmol}, 77 \%$; ${ }^{1} \mathrm{H}-\mathrm{NMR}:(250.1 \mathrm{MHz}$, $\left.\mathrm{CDCl}_{3}\right)$ : 7.76-7.70 (m, 2H, $\left.\mathrm{H}_{\mathrm{ar}}\right), 7.45-7.14\left(\mathrm{~m}, 6 \mathrm{H}, \mathrm{H}_{\mathrm{ar}}\right), 6.94-6.81\left(\mathrm{~m}, 3 \mathrm{H}, \mathrm{H}_{\mathrm{ar}}\right), 5.62(\mathrm{bs}, 1 \mathrm{H}, \mathrm{NH}), 3.56-3.47$ $\left(\mathrm{m}, 4 \mathrm{H}, \mathrm{CH}_{2}\right), 2.79\left(2 \mathrm{H},{ }^{3} \mathrm{H}_{\mathrm{HH}}=6.8 \mathrm{~Hz}, \mathrm{CH}_{2}\right)$ ppm; ${ }^{13} \mathrm{C}-\mathrm{NMR}:\left(75.4 \mathrm{MHz}, \mathrm{CDCl}_{3}\right): \delta=170.9,169.5,132.4$, $132.3,130.3,130.2,126.6,124.6,124.5$ (d), 122.0, 121.5, 116.7 (d), 115.9, 115.6, 113.8, 113.5, 109.0, 108.7, 40.8, 36.6, 35.4 ppm; $t_{R}: 11.3$ min (method A), purity: 97\%, HRMS: measured: 425.11260, calculated: $425.11298, \Delta \mathrm{m}: 0.89 \mathrm{ppm},\left[\mathrm{M}+\mathrm{H}^{+}\right]$.

methyl 4-((2-(4-(benzo[d]thiazol-2-yloxy)-2-fluorphenyl)acetamido) methyl)benzoate (21): procedure $\mathrm{C}$, educts: methyl 4-((2-(2-fluoro-4-hydroxyphenyl)acetamido)methyl)benzoate, 1-bromo2-isothiocyanatobenzene; $\mathrm{C}_{24} \mathrm{H}_{19} \mathrm{FN}_{2} \mathrm{O}_{4} \mathrm{~S} ; \mathrm{MW}: 450.48 \mathrm{~g} / \mathrm{mol}$; yield: $127 \mathrm{mg}, 0.28 \mathrm{mmol}, 51 \%$; ${ }^{1} \mathrm{H}$-NMR: $\left(400.1 \mathrm{MHz}, \mathrm{CDCl}_{3}\right)$ : 8.01-7.97 (m, 2H, $\left.\mathrm{H}_{\mathrm{ar}}\right), 7.75-7.69\left(\mathrm{~m}, 2 \mathrm{H}, \mathrm{H}_{\mathrm{ar}}\right), 7.44-7.27\left(\mathrm{~m}, 6 \mathrm{H}, \mathrm{H}_{\mathrm{ar}}\right), 7.24-7.17(\mathrm{~m}$, $\left.1 \mathrm{H}, \mathrm{H}_{\mathrm{ar}}\right), 5.99-5.94(\mathrm{~m}, 1 \mathrm{H}, \mathrm{NH}), 4.51\left(\mathrm{~d}, 2 \mathrm{H}, 3_{\mathrm{HH}}=6.0 \mathrm{~Hz}, \mathrm{CH}_{2}\right), 3.83\left(\mathrm{~s}, 3 \mathrm{H}, \mathrm{CH}_{3}\right), 3.60\left(\mathrm{~d}, 2 \mathrm{H},{ }^{4} \mathrm{~J}_{\mathrm{HH}}=1.1\right.$ $\left.\mathrm{Hz}, \mathrm{CH}_{2}\right) ;{ }^{13} \mathrm{C}-\mathrm{NMR}:\left(75.4 \mathrm{MHz}, \mathrm{CDCl}_{3}\right): \delta=169.6,154.7,154.6,148.9,143.1,132.5,132.4,130.2,127.5$, 
126.6, 124.6, 122.03, 121.5, 116.6 (d), 109.0, 108.9, 52.2, 42.9, $36.2 \mathrm{ppm} ; \mathrm{t}_{\mathrm{R}}: 10.6 \min (\operatorname{method} A)$, purity: 97\%, HRMS: measured: 451.11201 , calculated: $451.11223, \Delta \mathrm{m}: 0.49 \mathrm{ppm},\left[\mathrm{M}+\mathrm{H}^{+}\right]$.

2-(4-(benzo[d]thiazol-2-yloxy)-2-fluorophenyl)- $\mathrm{N}$-((6-fluoro-1H-indol-3-yl)methyl)acetamide (22): procedure C, educts: $\mathrm{N}$-((6-fluoro-1H-indol-3-yl)methyl)-2-(2-fluoro-4-hydroxyphenyl)acetamide, 1bromo-2-isothiocyanatobenzene; $\mathrm{C}_{24} \mathrm{H}_{17} \mathrm{~F}_{2} \mathrm{~N}_{3} \mathrm{O}_{2} \mathrm{~S} ; \mathrm{MW}: 449.47 \mathrm{~g} / \mathrm{mol}$; yield: $265 \mathrm{mg}, 0.59 \mathrm{mmol}, 66 \%$; $\left.{ }^{1} \mathrm{H}-\mathrm{NMR}:(400.1 \mathrm{MHz}, \mathrm{DMSO}): 11.00(\mathrm{~s}, 1 \mathrm{H}, \mathrm{NH}), 8.43\left(\mathrm{t}, 1 \mathrm{H},{ }^{3}\right)_{\mathrm{HH}}=5.4 \mathrm{~Hz}, \mathrm{NH}\right), 7.95\left(\mathrm{dd}, 1 \mathrm{H},{ }^{3} \mathrm{H}_{\mathrm{HH}}=7.9\right.$ $\left.\mathrm{Hz},{ }^{4} J_{\mathrm{HH}}=2.9 \mathrm{~Hz}, \mathrm{H}_{\mathrm{ar}}\right), 7.75\left(\mathrm{dd}, 1 \mathrm{H},{ }^{3} J_{\mathrm{HH}}=8.1 \mathrm{~Hz},{ }^{4} J_{\mathrm{HH}}=2.9 \mathrm{~Hz}, \mathrm{H}_{\mathrm{ar}}\right), 7.55-7.49\left(\mathrm{~m}, 4 \mathrm{H}, \mathrm{H}_{\mathrm{ar}}\right), 7.36-7.32(\mathrm{~m}$, $\left.1 \mathrm{H}, \mathrm{H}_{\mathrm{ar}}\right), 7.28-7.25\left(\mathrm{~m}, 2 \mathrm{H}, \mathrm{H}_{\mathrm{ar}}\right), 7.15\left(\mathrm{dd}, 1 \mathrm{H}, 3^{3} \mathrm{HH}_{1}=10.2 \mathrm{~Hz},{ }^{4} J_{\mathrm{HH}}=4.1 \mathrm{~Hz}, \mathrm{H}_{\mathrm{ar}}\right), 6.88-6.83\left(\mathrm{~m}, 1 \mathrm{H}, \mathrm{H}_{\mathrm{ar}}\right)$, $4.44\left(\mathrm{~d}, 2 \mathrm{H},{ }^{3} \mathrm{~J}_{\mathrm{HH}}=5.6 \mathrm{~Hz}, \mathrm{CH}_{2}\right), 3.58\left(\mathrm{~s}, 2 \mathrm{H}, \mathrm{CH}_{2}\right) ;{ }^{13} \mathrm{C}-\mathrm{NMR}:(100.6 \mathrm{MHz}, \mathrm{DMSO}): \delta=171.3,168.5,148.4$, $136.3,136.1,132.6$ (d), 131.9, 126.5, 124.4, 123.3, 122.2, 121.3, 119.8, 119.7, 116.6 (d), 112.5, 108.8, 108.5, 107.1, 106,9, 97.5, 97.2, 34.8, $34.2 \mathrm{ppm} ; \mathrm{t}_{\mathrm{R}}: 10.55 \mathrm{~min}$ (method A), purity: $90 \%$, HRMS: measured: 488.06406, calculated: 488.06411, $\Delta \mathrm{m}: 0.10 \mathrm{ppm},\left[\mathrm{M}+\mathrm{K}^{+}\right]$.

\section{LTA $_{4} \mathrm{H}$ expression and purification}

The cloning, expression and purification of the recombinant human leukotriene A4 hydrolase $\left(\mathrm{LTA}_{4} \mathrm{H}\right)$ with a hexahistidin-tag was described by Moser et. al. ${ }^{1}$ The published expression and purification protocol was slightly modified in the performed experiments. In brief, $\mathrm{LTA}_{4} \mathrm{H}$ was overexpressed in $\mathrm{E}$. coli BL21(DE3)RIPL-Codon Plus cells (Invitrogen).Cells were grown in 1L culture of Miller's LB Broth Base $^{\mathrm{TM}}$ (Invitrogen) at $37^{\circ} \mathrm{C}$ and $180 \mathrm{rpm}$ till an $\mathrm{OD}_{600}$ of approximately 0.8 before protein expression was induced by the addition of $400 \mu \mathrm{M}$ IPTG (Isopropyl- $\beta$-D-thiogalactopyranosid, AppliChem). Temperature was reduced to $21^{\circ} \mathrm{C}$ and cultures were harvested the next day by centrifugation. Generated cell pellets were suspended in $\mathrm{LTA}_{4} \mathrm{H}$ buffer A $(50 \mathrm{mM}$ Tris, $500 \mathrm{mM} \mathrm{NaCl}$, and $20 \mathrm{mM}$ imidazole, $\mathrm{HCl} \mathrm{pH} \mathrm{8)} \mathrm{supplemented} \mathrm{with} \mathrm{approximately} 0.5 \mathrm{~g}$ DNAse (AppliChem) and an EDTA-free protease inhibitor complete tablet (Roche) before lysis. The cell debris were removed by consecutive centrifugation. Supernatant was sterile filtered $(0.45 \mu \mathrm{M}$ syringe filter) before further purification by immobilized metal ion affinity chromatography on a His-Trap HP column (GE Healthcare) using a step gradient protocol occurred. As running buffer buffer $\mathrm{A}$ was used, while $\mathrm{LTA}_{4} \mathrm{H}$ buffer $\mathrm{B}$ (identical to buffer $A$ with an imidazole concentration of $400 \mathrm{mM}$ ) was used as elution buffer. Protein was eluted at $100 \% \mathrm{LTA}_{4} \mathrm{H}$ buffer $\mathrm{B}$. Fractions containing the protein were further purified by a Superdex 200 column (GE Healthcare). As running buffer $\mathrm{LT}_{4} \mathrm{H}$ buffer $\mathrm{C}(50 \mathrm{mM}$ Tris, $500 \mathrm{mM} \mathrm{NaCl}, \mathrm{HCl} \mathrm{pH} \mathrm{8)} \mathrm{was}$ used. The purity of the fractions containing $\mathrm{LTA}_{4} \mathrm{H}$ was analyzed by SDS-PAGE. Pure fractions were pooled and the concentration determined by Nanodrop (Implen, Muenchen, Germany). Aliquots of the protein were flash frozen in liquid nitrogen and stored at $-80^{\circ} \mathrm{C}$.

\section{$\mathrm{LTA}_{4} \mathrm{H}$ activity assay with L-arginine-7-amido-4-methylcoumarine}

The fluorescence-based $\mathrm{LTA}_{4} \mathrm{H}$ activity assay was performed according the protocol published by Wittmann et.al. ${ }^{2}$ using the non-fluorescent L-arginine-7-amino-4-methylcoumarine (abcr, Karlsruhe, Germany) as substrate which is cleaved by the $\mathrm{LTA}_{4} \mathrm{H}$ in L-arginine as well as the fluorescent amino-4methylcoumarine. The assay was performed in black polystyrol 96-well plates in a final volume of $100 \mu \mathrm{L}$. LTA ${ }_{4} \mathrm{H}$ buffer $\mathrm{C}$ supplemented with $0.01 \%$ Triton-X 100 was used and resulting from the addition of the ligands the final samples contained $1 \%$ DMSO. For determination of $I C_{50}$ values $0.25 \mu \mathrm{M}$ protein were incubated with different concentrations of inhibitor for 30 minutes. Buffer containing DMSO and Triton-X 100 but no protein was used for negative control, while a sample with protein but without compound (with pure DMSO) was used as positive control. The substrate was added ( $200 \mu \mathrm{M}$ final concentration) after the incubation and change in the fluorescence intensity was measured at Tecan Infinite F200 Pro Plate Reader $\left(\lambda_{\mathrm{em}}=360 \mathrm{~nm}, \lambda_{\mathrm{ex}}=465 \mathrm{~nm}\right.$ ) for 30 minutes (one point every minute) at room temperature. Percent inhibition was calculated by referencing the slope in the linear 
phase of the reactions to the slopes of negative and positive controls in MS Excel and fitting the obtained data with a sigmoidal dose response curve fit (variable slope with 4 parameters) in Graph Pad Prism 5.3 to determine $\mathrm{IC}_{50}$ values.

\section{sEH expression and purification}

The sEH full length (sEH-FL; aa1-aa555) for activity assays as well as the sEH-Hydrolase domain (aa222aa555) (sEH-Hyd) used in the crystallization experiments were expressed and purified as published previously by Klingler et. al. ${ }^{3}$ and Lukin et. al. ${ }^{4}$ The same expression constructs were used for the expression $\mathrm{SEH}$ hydrolase and $\mathrm{SEH}-\mathrm{FL}$ described in both publications. In brief, both proteins were expressed in E. coli BL21-(DE3) cells grown in ZYP5052 autoinduction media with kanamycin as selection marker. Cultures were incubated at $37^{\circ} \mathrm{C}$ and $180 \mathrm{rpm}$ for $2 \mathrm{~h}$, before transferred to a $16{ }^{\circ} \mathrm{C}$ shaker. The cells were harvested after $36 \mathrm{~h}$ by centrifugation. Cell pellets were stored at $-20^{\circ} \mathrm{C}$.

Bacterial pellets were thawed and re-suspended in sEH buffer A $(50 \mathrm{mM}$ Tris/ $\mathrm{HCl} \mathrm{pH} \mathrm{8,} 500 \mathrm{mM} \mathrm{NaCl}$, $70 \mathrm{mM}$ imidazole/ $\mathrm{HCl} \mathrm{pH} \mathrm{7)} \mathrm{with} \mathrm{one} \mathrm{tablet} \mathrm{of} \mathrm{Complete} \mathrm{EDTA} \mathrm{free} \mathrm{protease} \mathrm{inhibitor} \mathrm{mix} \mathrm{(Roche,}$ Basel, Switzerland) and a trace amount of DNAse I (Applichem, Darmstadt, Germany). The resuspended cells were lysed and cell debris were removed by centrifugation. The supernatant was purified by nickel affinity chromatography using a step gradient protocol. As running buffer A was used, while SEH buffer B (identical to SEH buffer A with an imidazole concentration of $400 \mathrm{mM}$ ) was used as elution buffer. The fractions containing the target protein were pooled. The sEH-FL was dialysed for 18-24 hours at $4^{\circ} \mathrm{C}$ against 100 fold excess of sEH buffer $\mathrm{C}(50 \mathrm{mM}$ Tris, $50 \mathrm{mM} \mathrm{NaCl}, \mathrm{HCl} \mathrm{pH} 8$ ) for activity assays using a $3500 \mathrm{kDa}$ membrane. The dialysis buffer was exchanged twice during the dialysis period. The protein samples intended for the use in assays were mix with glycerol to a final concentration of $20 \%(\mathrm{v} / \mathrm{v})$, before the concentration was determined by Nanodrop and aliquots were flash frozen in liquid nitrogen and stored at $-80{ }^{\circ} \mathrm{C}$. The $\mathrm{sEH}-\mathrm{Hyd}$ was concentrated 3 fold by ultrafiltration to a final volume of $5 \mathrm{~mL}$ through $3000 \mathrm{Da}$ cut-off membrane. The concentrated protein was applied onto the with sEH buffer $\mathrm{D}(50 \mathrm{mM}$ Tris/ $\mathrm{HCl} \mathrm{pH} \mathrm{8,} 500 \mathrm{mM} \mathrm{NaCl}$ ) pre-equilibrated Superdex 75 HiLoad 16/600 column (GE Healthcare, Germany) and separated at the flow of $1 \mathrm{~mL} / \mathrm{min}$ in the sEH buffer D. sEH-Hyd in sEH buffer D was dialyzed in sEH buffer $E(50 \mathrm{mM} \mathrm{NaCl}, 50 \mathrm{mM}$ sodium phosphate, $10 \%(\mathrm{v} / \mathrm{v})$ glycerol (98\%), 2 mM DTT, pH 7.4 ) before concentrated by ultrafiltration (3000 Da cut-off membrane) to $5-10 \mathrm{mg} / \mathrm{mL}$ and flash frozen in liquid nitrogen. Frozen protein samples were stored at $-80^{\circ} \mathrm{C}$.

\section{sEH-H activity assay with PHOME}

The fluorescence based activity assay was performed according to a modified version of the protocol published by Lukin et.al. ${ }^{4}$ and Hahn et. al. ${ }^{5}$ In brief, the assay was performed in black flat bottom $96-$ well plates with a final assay volume of $100 \mu \mathrm{M}$ and the non-fluorescent PHOME (3-phenyl-cyano-(6methoxy-2-naphthalenyl)methyl ester-2-oxirane-acetic acid) as the substrate. The substrate can be hydrolyzed by the SEH to the fluorescent 6 -methoxynaphtaldehyde ${ }^{6}$ which is monitored over the course of the reaction at $\lambda_{\mathrm{em}}=330 \mathrm{~nm}$ and $\lambda_{\mathrm{ex}}=465 \mathrm{~nm}$ by a Tecan Infinite F200 Pro plate reader. For the assay recombinant human full length $\mathrm{SEH}\left(3 \mathrm{nM} \mathrm{c}_{\text {final }}\right.$ ) was dissolved in $\mathrm{pH} 7$ Bis-Tris buffer with $0.1 \mathrm{mg} / \mathrm{ml} \mathrm{BSA}$ as well as Triton-X 100 in a final concentration of $0.01 \%(\mathrm{w} / \mathrm{v}) .89 \mu \mathrm{l}$ of protein mix were incubated for $30 \mathrm{~min}$ at room temperature with $1 \mu \mathrm{L}$ of different concentrations of compounds in DMSO (final DMSO concentration 1\%). The reaction was started by the addition of $10 \mu$ l substrate solution (to the final concentration $50 \mu \mathrm{M}$ ). The reaction was monitored for 30 mins (one point every minute). A blank control (no protein and no compound, but DMSO) as well as a positive control (no 
compound, but DMSO) was carried out as well. All measurements were performed in triplicates. Data analysis was performed according to protocol of the $\mathrm{LTA}_{4} \mathrm{H}$ activity assay with 7-amido-4methylcoumarine described above.

\section{Water solubility assay}

To determine the water solubility limit dilution series of the corresponding compounds in DMSO were performed. $1 \mu \mathrm{L}$ of the DMSO solution was placed into clear polystyrene microplates and diluted with $99 \mu \mathrm{L}$ DPBS buffer ( $\mathrm{pH} 7.4)$ with $0.01 \%(\mathrm{w} / \mathrm{v})$ Triton X-100. As reference three wells with $1 \mu \mathrm{L}$ pure DMSO in $99 \mu \mathrm{L}$ buffer was used. The absorption of the wells was measured by a Tecan infinite M200 at $650 \mathrm{~nm}$. After determination of the means of each triplicate the values were compared to the mean of the reference. If the absorption values of the compound wells are higher than the reference the compound is not solved completely. The change of absorptions compared to the reference marks the solubility limit.

Table S 1: results of the water solubility assay.

\begin{tabular}{|c|l|}
\hline Compound & solubility limit (DBPS-buffer, pH 7.4) \\
\hline $\mathbf{3}$ & between 10 and $30 \mu \mathrm{M}$ \\
\hline $\mathbf{5}$ & between 10 and $30 \mu \mathrm{M}$ \\
\hline $\mathbf{6}$ & between 10 and $30 \mu \mathrm{M}$ \\
\hline $\mathbf{7}$ & between 10 and $30 \mu \mathrm{M}$ \\
\hline $\mathbf{8}$ & between 10 and $30 \mu \mathrm{M}$ \\
\hline $\mathbf{9}$ & between 10 and $30 \mu \mathrm{M}$ \\
\hline $\mathbf{1 0}$ & between 30 and $100 \mu \mathrm{M}$ \\
\hline $\mathbf{1 3}$ & between 10 and $30 \mu \mathrm{M}$ \\
\hline $\mathbf{1 4}$ & between 10 and $30 \mu \mathrm{M}$ \\
\hline $\mathbf{1 5}$ & between 3 and $10 \mu \mathrm{M}$ \\
\hline $\mathbf{1 6}$ & between 10 and $30 \mu \mathrm{M}$ \\
\hline $\mathbf{1 7}$ & between 10 and $30 \mu \mathrm{M}$ \\
\hline $\mathbf{1 8}$ & between 3 and $10 \mu \mathrm{M}$ \\
\hline $\mathbf{1 9}$ & between 10 and $30 \mu \mathrm{M}$ \\
\hline $\mathbf{2 0}$ & between 10 and $30 \mu \mathrm{M}$ \\
\hline $\mathbf{2 1}$ & between 10 and $30 \mu \mathrm{M}$ \\
\hline $\mathbf{2 2}$ & between 3 and $10 \mu \mathrm{M}$ \\
\hline & \\
\hline
\end{tabular}


Determination of cLogP values occurred via a web-based tool. ${ }^{7}$

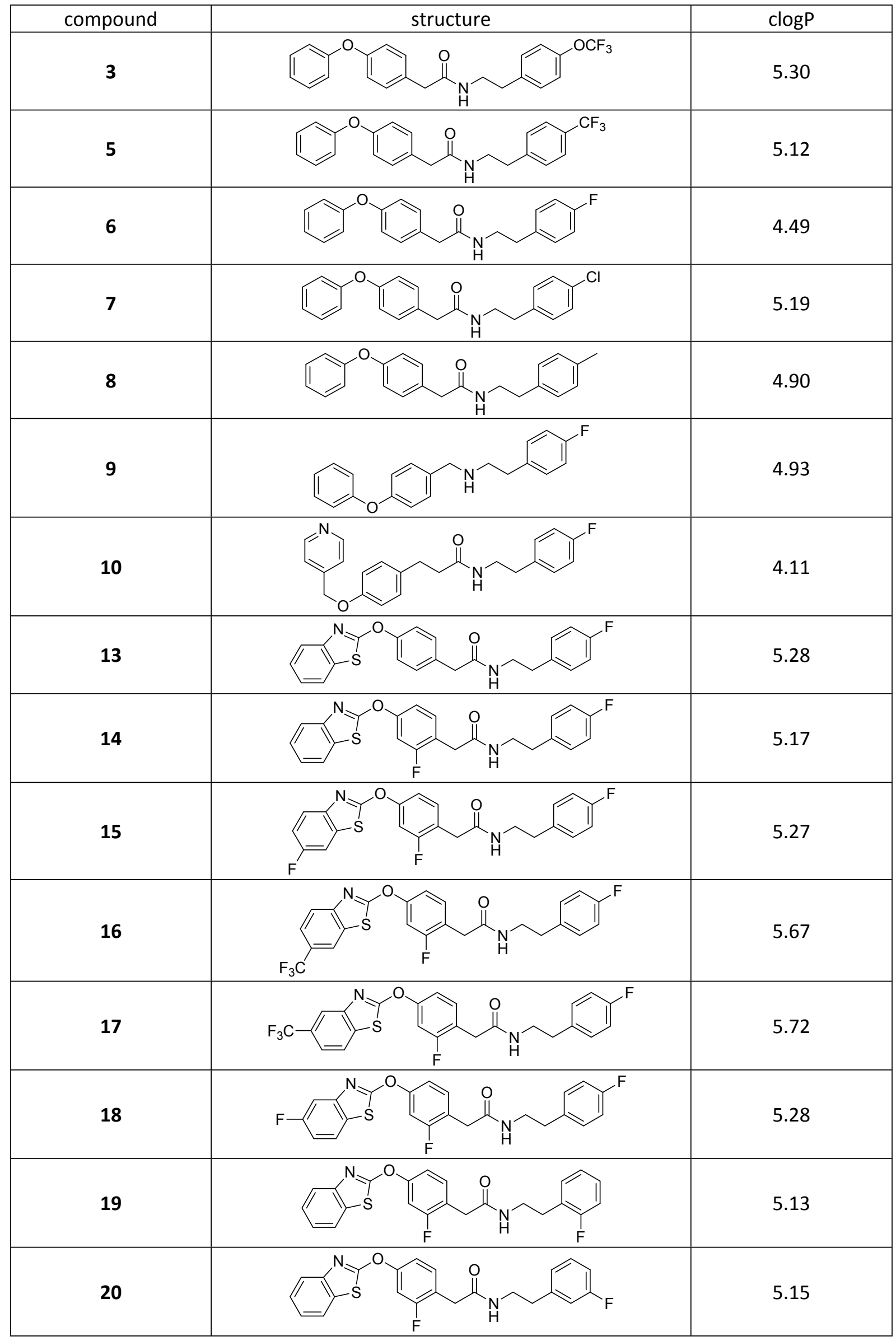




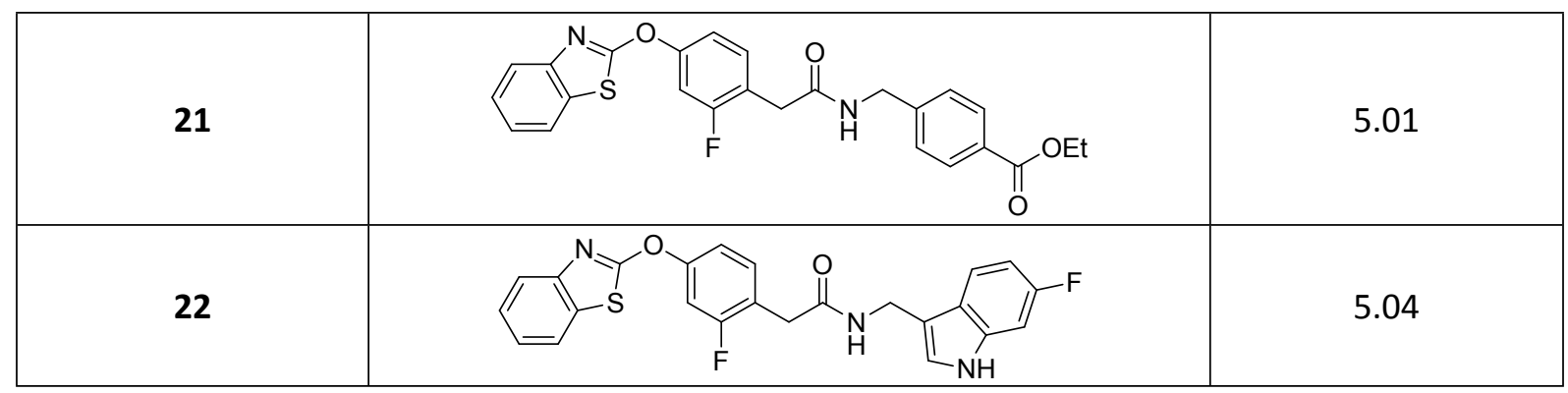

\section{Co-crystallization of 9 with the C-terminal domain of sEH}

The protocol for the crystallization of the C-terminal domain is biased of the original publication of Xing et al. ${ }^{8}$ and the modified protocol used for the co-crystallization of compound $\mathbf{7}$ is identical to the protocols published by Lukin et.al. ${ }^{4}$ as well as Hiesinger and Kramer et.al. ${ }^{9}$ and is referred in the following. The C-terminal sEH domain was crystallized over the course of a month at $277 \mathrm{~K}$ by sittingdrop vapor diffusion. $1 \mu \mathrm{L}$ of the protein solution $(5-10 \mathrm{mg} / \mathrm{mL}, 50 \mathrm{mM} \mathrm{NaCl}, 50 \mathrm{mM}$ sodium phosphate, $10 \%(\mathrm{v} / \mathrm{v})$ glycerol (98\%), $2 \mathrm{mM}$ DTT at $\mathrm{pH} 7.4$ was mixed $1: 1$ with precipitant mixture $(23 \%-28 \%(\mathrm{w} / \mathrm{v})$ polyethylenglycol (PEG) 6000, $70 \mathrm{mM}$ ammonium acetate, $200 \mathrm{mM}$ magnesium acetate, $100 \mathrm{mM}$ sodium cacodylate at $\mathrm{pH}$ 6.1-6.5). For soaking of the crystals, a saturated DMSO inhibitor solution of 9 was diluted 1:100 in PEG 400, before a second 1:9 dilution step in PEG 400/ precipitant mixture (3:7). Protein crystals where transferred into the soaking solution for $24 \mathrm{~h}$, before the crystals were picked and flash frozen in the liquid nitrogen.

X-ray diffraction data of a single crystal was collected at the beamline station ID29 at the European Synchrotron Radiation Facility (ESRF), Grenoble, France. All diffraction data was obtained from a single crystal. The data was processed with XDS software package ${ }^{10}$. The initial structure was obtained using the Phaser program ${ }^{11}$ within PHENIX software package ${ }^{12}$ where polypeptide model from the PDB record $4 \mathrm{JNC}$ where coordinates for heteroatoms (water and ligands) were excluded from the starting model. After several iterative rounds of model building with $\operatorname{Coot}^{13}$ and the model refinement using the PHENIX software package ${ }^{14}$ a value of 0.18 for $R_{\text {work }}$ and a value of 0.24 for $R_{\text {free }}$ were reached after the final round of refinement. Cif file the compound used during the refinement was generated using the elbow tool ${ }^{15}$. The overall electron density of the ligand was relatively low. In addition, density indicated that one additional binding conformation of the ligand might be present in lower abundance in the binding pocket, resulting in a relatively low RSCC score for the modeled main binding conformation. The graphical representations were made using MOE. Statistics of data collection and structural refinement are summarized in Table S1 which was generated using the PHENIX table one tool. The coordinates and structure-factor amplitudes of the structure have been deposited in the Protein Data Bank as entry 6HGW (9).

Table S1. Data collection and refinement statistics of SEH-H in complex with compound 9. Statistics for the highest-resolution shell (10\% of reflections) are shown in parentheses.

Wavelength

$53.26-2.407(2.493-$

Resolution range

Space group 


\begin{tabular}{|c|c|}
\hline & 80.1892 .42106 .53 \\
\hline Unit cell & 9090 \\
\hline Total reflections & 203034 (19680) \\
\hline Unique reflections & 15703 (1526) \\
\hline Multiplicity & $12.9(12.9)$ \\
\hline Completeness (\%) & $99.92(100.00)$ \\
\hline Mean I/sigma(I) & $15.34(2.08)$ \\
\hline Wilson B-factor & 52.99 \\
\hline R-merge & $0.1115(1.331)$ \\
\hline R-meas & $0.1162(1.386)$ \\
\hline R-pim & $0.03234(0.3835)$ \\
\hline CC1/2 & $0.998(0.728)$ \\
\hline $\mathrm{CC}^{*}$ & $1(0.918)$ \\
\hline $\begin{array}{l}\text { Reflections used } \\
\text { in refinement }\end{array}$ & $15694(1526)$ \\
\hline $\begin{array}{l}\text { Reflections used } \\
\text { for R-free }\end{array}$ & $1569(153)$ \\
\hline R-work & $0.1804(0.2909)$ \\
\hline R-free & $0.2387(0.3532)$ \\
\hline CC(work) & $0.962(0.863)$ \\
\hline $\mathrm{CC}($ free $)$ & $0.940(0.754)$ \\
\hline $\begin{array}{l}\text { Number of non- } \\
\text { hydrogen atoms }\end{array}$ & 2623 \\
\hline macromolecules & 2571 \\
\hline ligands & 24 \\
\hline solvent & 28 \\
\hline Protein residues & 319 \\
\hline
\end{tabular}




\begin{tabular}{lc}
$\begin{array}{l}\text { RMS(bonds) } \\
\text { RMS(angles) }\end{array}$ & 0.005 \\
$\begin{array}{l}\text { Ramachandran } \\
\text { favored (\%) }\end{array}$ & 0.74 \\
$\begin{array}{l}\text { Ramachandran } \\
\text { allowed (\%) }\end{array}$ & 3.15 \\
$\begin{array}{l}\text { Ramachandran } \\
\text { outliers (\%) }\end{array}$ & 0.32 \\
$\begin{array}{c}\text { Rotamer outliers } \\
\text { (\%) }\end{array}$ & 0.00 \\
Clashscore \\
$\begin{array}{c}\text { Average B-factor } \\
\text { guroups } \\
\text { macromolecules }\end{array}$ & 6.32 \\
ligands & 62.72 \\
solvent & 102.72 \\
\hline
\end{tabular}

Proposed binding mode of 13 in the binding site of $\mathrm{LTA}_{4} \mathrm{H}$

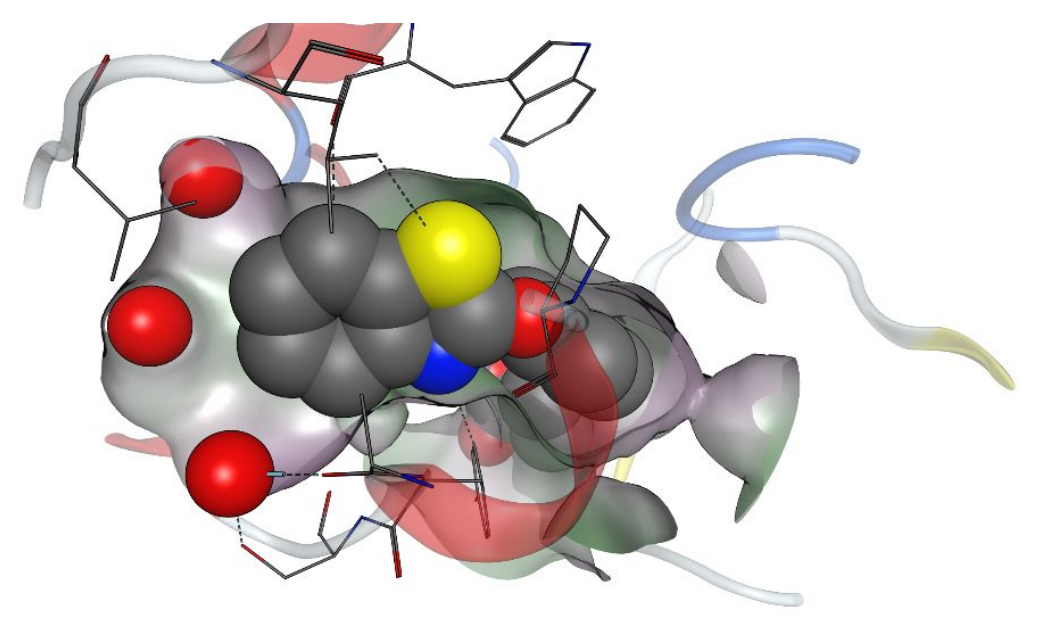

Figure S1: A benzthiazole-based inhibitor in the binding pocket of $L T A_{4} H(P D B \text { code } 6 E N C)^{16}$ revealed a water cluster (red balls), which might be disturbed by substituents in the 5- and 6-position of the benzothiazole moiety. 


\section{Cellular assays in macrophages}

\section{Cells and cell isolation}

Human peripheral blood (University Hospital Jena, Germany) was withdrawn from fasted (12 h) healthy adult donors (18-65 years) that had not taken anti-inflammatory drugs during the last 10 days, by venipuncture in heparinized tubes (16 IE heparin/ $\mathrm{ml}$ blood), with written informed consent. The experimental protocol was approved by the ethical committee of the University Hospital Jena. All methods were performed in accordance with the relevant guidelines and regulations. In brief, the blood was centrifuged at $4000 \times \mathrm{g}$ for $20 \mathrm{~min}$ at $20{ }^{\circ} \mathrm{C}$ for preparation of leukocyte concentrates. Leukocyte concentrates were then subjected to dextran sedimentation and centrifugation on FicollHistopaque 1077-1 (Sigma-Aldrich) cushions. Monocytes were isolated from peripheral blood mononuclear cell fraction that was obtained after Ficoll-Histopaque 1077-1 centrifugation of leukocyte concentrates and adherence for $1.5 \mathrm{~h}$ at $37^{\circ} \mathrm{C}$ to culture flasks (Greiner, Nuertingen, Germany). The monocyte purity was $>85 \%$, defined by forward- and side-light scatter properties and detection of the CD14 surface molecule by flow cytometry (BD FACS Calibur, Heidelberg, Germany).

\section{Differentiation of monocytes to macrophages and macrophage polarization}

The differentiation of monocytes to macrophages and polarization towards $\mathrm{M} 1$ and $\mathrm{M} 2$ was performed as described. ${ }^{17} \mathrm{M} 1$-macrophages were obtained by incubating monocytes with $20 \mathrm{ng} / \mathrm{ml} \mathrm{GM}$-CSF (Peprotech, Hamburg, Germany) for 6 days in RPMI 1640 supplemented with 10\% FCS, 2 mmol/L Lglutamine, penicillin $(100 \mathrm{U} / \mathrm{mL})$ and streptomycin $(100 \mu \mathrm{g} / \mathrm{mL})$, followed by $100 \mathrm{ng} / \mathrm{ml} \mathrm{LPS}$ and $20 \mathrm{ng} / \mathrm{ml} \mathrm{INF-} \gamma$ (Peprotech) treatment for another $48 \mathrm{~h}$. M2 were obtained by incubating monocytes with $20 \mathrm{ng} / \mathrm{ml} \mathrm{M-CSF}$ (Peprotech) for 6 days and subsequent treatment with $20 \mathrm{ng} / \mathrm{ml} \mathrm{IL-4} \mathrm{(Peprotech)}$ for additional $48 \mathrm{~h}$. Correct polarization and purity of macrophages was routinely checked by flow cytometry (FACS Canto Plus flow cytometer, BD Bioscience) as reported ${ }^{18}$ using the following antibodies: FITC anti-human CD14 (2 $\mathrm{gg} /$ test, clone M5E2, BD Bioscience), PE anti-human CD54 (1 $\mu \mathrm{g} / \mathrm{test}$, clone HA58, BD Bioscience), APC-H7 anti-human CD80 (0.25 $\mu \mathrm{g} /$ test, clone L307.4, BD Bioscience), PE-Cy7 anti-human CD163 (2 $\mathrm{gg} /$ test, clone RM3/1, Biolegend, San Diego, CA), PerCPefluor710 anti-human CD206 (0.06 $\mu \mathrm{g} /$ test, clone 19.2, Biosciences, San Diego, CA).

\section{LM metabololipidomics in human macrophages}

Macrophages $\left(2 \times 10^{6} / \mathrm{ml}\right)$ were stimulated in PBS containing $1 \mathrm{mM} \mathrm{CaCl}$. Compounds or vehicle control (0.1\% DMSO) were added 10 min prior stimulation with $E$. coli (serotype O6:K2:H1, ratio 1:50, M1/M2:E. coli) for $180 \mathrm{~min}$ at $37{ }^{\circ} \mathrm{C}$. Supernatants were transferred to $2 \mathrm{ml}$ of ice-cold methanol containing $10 \mu \mathrm{l}$ of deuterium-labeled internal standards (200 nM d $\mathrm{d}_{8}-5 \mathrm{~S}-\mathrm{HETE}, \mathrm{d}_{4}-\mathrm{LTB}_{4}, \mathrm{~d}_{5}-\mathrm{LXA}_{4}, \mathrm{~d}_{5}-$ RvD2, $d_{4}-P_{G E}$ and $10 \mu \mathrm{M} \mathrm{d}_{8}-\mathrm{AA}$; Cayman Chemical/Biomol GmbH, Hamburg, Germany) to facilitate quantification. Sample preparation was conducted as described previously..$^{18}$ In brief, samples were kept at $-20^{\circ} \mathrm{C}$ for $60 \mathrm{~min}$ to allow protein precipitation. After centrifugation $\left(1200 \mathrm{~g}, 4^{\circ} \mathrm{C}, 10 \mathrm{~min}\right) 8 \mathrm{ml}$ acidified $\mathrm{H}_{2} \mathrm{O}(\mathrm{pH} 3.5)$ was added and subjected to solid phase extraction. Solid phase cartridges (Sep$\mathrm{Pak}^{\circ} \mathrm{Vac} 6 \mathrm{cc} 500 \mathrm{mg} / 6 \mathrm{ml} \mathrm{C} 18$; Waters, Milford, MA) were equilibrated with $6 \mathrm{ml}$ methanol and $2 \mathrm{ml}$ $\mathrm{H}_{2} \mathrm{O}$ before samples were loaded onto columns. After washing with $6 \mathrm{ml} \mathrm{H}_{2} \mathrm{O}$ and additional $6 \mathrm{ml} \mathrm{n}$ hexane, LM were eluted with $6 \mathrm{ml}$ methyl formiate. Finally, the samples were brought to dryness using an evaporation system (TurboVap LV, Biotage, Uppsala, Sweden) and resuspended in $100 \mu$ methanolwater (50/50, v/v) for UPLC-MS-MS automated injections. LM profiling was analyzed with an Acquity ${ }^{\mathrm{TM}}$ UPLC system (Waters, Milford, MA) and a QTRAP 5500 mass spectrometer (AB Sciex, Darmstadt, 
Germany) equipped with a Turbo $V^{\mathrm{TM}}$ Source and electrospray ionization (ESI). LM were eluted using an ACQUITY UPLC BEH C18 column (1.7 $\mu \mathrm{m}, 2.1 \times 100 \mathrm{~mm}$; Waters, Eschborn, Germany) as reported before. ${ }^{18}$ The QTRAP 5500 mass spectrometer was operated in negative ionization mode using scheduled multiple reaction monitoring (MRM) coupled with information-dependent acquisition. The scheduled MRM window was $60 \mathrm{sec}$, optimized LM parameters were adopted, and the curtain gas pressure was set to $35 \mathrm{psi}$. The retention time and at least six diagnostic ions for each LM were confirmed by means of an external standard (Cayman Chemicals). Quantification was achieved by calibration curves for each LM. Linear calibration curves were obtained for each LM and gave $r^{2}$ values of 0.998 or higher (for fatty acids 0.95 or higher).

\section{References}

(1) Moser, D.; Wittmann, S. K.; Kramer, J.; Blöcher, R.; Achenbach, J.; Pogoryelov, D.; Proschak, E. PENG: A Neural Gas-Based Approach for Pharmacophore Elucidation. Method Design, Validation, and Virtual Screening for Novel Ligands of LTA4H. J Chem Inf Model 2015, 55 (2), 284-293. https://doi.org/10.1021/ci500618u.

(2) Wittmann, S. K.; Kalinowsky, L.; Kramer, J. S.; Bloecher, R.; Knapp, S.; Steinhilber, D.; Pogoryelov, D.; Proschak, E.; Heering, J. Thermodynamic Properties of Leukotriene A4 Hydrolase Inhibitors. Bioorg. Med. Chem. 2016, 24 (21), 5243-5248. https://doi.org/10.1016/j.bmc.2016.08.047.

(3) Klingler, F.-M.; Wolf, M.; Wittmann, S.; Gribbon, P.; Proschak, E. Bacterial Expression and HTS Assessment of Soluble Epoxide Hydrolase Phosphatase. J Biomol Screen 2016, 21 (7), 689-694. https://doi.org/10.1177/1087057116637609.

(4) Lukin, A.; Kramer, J.; Hartmann, M.; Weizel, L.; Hernandez-Olmos, V.; Falahati, K.; Burghardt, I.; Kalinchenkova, N.; Bagnyukova, D.; Zhurilo, N.; et al. Discovery of Polar Spirocyclic Orally Bioavailable Urea Inhibitors of Soluble Epoxide Hydrolase. Bioorg. Chem. 2018, 80, 655-667. https://doi.org/10.1016/j.bioorg.2018.07.014.

(5) Hahn, S.; Achenbach, J.; Buscató, E.; Klingler, F.-M.; Schroeder, M.; Meirer, K.; Hieke, M.; Heering, J.; Barbosa-Sicard, E.; Loehr, F.; et al. Complementary Screening Techniques Yielded Fragments That Inhibit the Phosphatase Activity of Soluble Epoxide Hydrolase. ChemMedChem 2011, 6 (12), 2146-2149. https://doi.org/10.1002/cmdc.201100433.

(6) Wolf, N. M.; Morisseau, C.; Jones, P. D.; Hock, B.; Hammock, B. D. Development of a HighThroughput Screen for Soluble Epoxide Hydrolase Inhibition. Anal. Biochem. 2006, 355 (1), 7180. https://doi.org/10.1016/j.ab.2006.04.045.

(7) Tetko, I. V.; Gasteiger, J.; Todeschini, R.; Mauri, A.; Livingstone, D.; Ertl, P.; Palyulin, V. A.; Radchenko, E. V.; Zefirov, N. S.; Makarenko, A. S.; et al. Virtual Computational Chemistry Laboratory--Design and Description. J. Comput. Aided Mol. Des. 2005, 19 (6), 453-463. https://doi.org/10.1007/s10822-005-8694-y.

(8) Xing, L.; McDonald, J. J.; Kolodziej, S. A.; Kurumbail, R. G.; Williams, J. M.; Warren, C. J.; O’Neal, J. M.; Skepner, J. E.; Roberds, S. L. Discovery of Potent Inhibitors of Soluble Epoxide Hydrolase by Combinatorial Library Design and Structure-Based Virtual Screening. J. Med. Chem. 2011, 54 (5), 1211-1222. https://doi.org/10.1021/jm101382t.

(9) Hiesinger, K.; Kramer, J. S.; Achenbach, J.; Moser, D.; Weber, J.; Wittmann, S. K.; Morisseau, C.; Angioni, C.; Geisslinger, G.; Kahnt, A. S.; et al. Computer-Aided Selective Optimization of Side Activities of Talinolol. ACS Med Chem Lett 2019, 10 (6), 899-903. https://doi.org/10.1021/acsmedchemlett.9b00075.

(10) Kabsch, W. XDS. Acta Crystallogr D Biol Crystallogr 2010, 66 (Pt 2), 125-132. https://doi.org/10.1107/S0907444909047337.

(11) McCoy, A. J.; Grosse-Kunstleve, R. W.; Adams, P. D.; Winn, M. D.; Storoni, L. C.; Read, R. J. Phaser Crystallographic Software. J Appl Cryst 2007, 40 (4), 658-674. https://doi.org/10.1107/S0021889807021206.

(12) Adams, P. D.; Afonine, P. V.; Bunkóczi, G.; Chen, V. B.; Davis, I. W.; Echols, N.; Headd, J. J.; Hung, L.-W.; Kapral, G. J.; Grosse-Kunstleve, R. W.; et al. PHENIX: A Comprehensive Python-Based 
System for Macromolecular Structure Solution. Acta Cryst D 2010, 66 (2), 213-221. https://doi.org/10.1107/S0907444909052925.

(13) Emsley, P.; Lohkamp, B.; Scott, W. G.; Cowtan, K. Features and Development of Coot. Acta Cryst D 2010, 66 (4), 486-501. https://doi.org/10.1107/S0907444910007493.

(14) Afonine, P. V.; Grosse-Kunstleve, R. W.; Echols, N.; Headd, J. J.; Moriarty, N. W.; Mustyakimov, M.; Terwilliger, T. C.; Urzhumtsev, A.; Zwart, P. H.; Adams, P. D. Towards Automated Crystallographic Structure Refinement with Phenix.Refine. Acta Cryst D 2012, 68 (4), 352-367. https://doi.org/10.1107/S0907444912001308.

(15) Moriarty, N. W.; Grosse-Kunstleve, R. W.; Adams, P. D. Electronic Ligand Builder and Optimization Workbench (ELBOW): A Tool for Ligand Coordinate and Restraint Generation. Acta Cryst D 2009, 65 (10), 1074-1080. https://doi.org/10.1107/S0907444909029436.

(16) Numao, S.; Hasler, F.; Laguerre, C.; Srinivas, H.; Wack, N.; Jäger, P.; Schmid, A.; Osmont, A.; Röthlisberger, P.; Houguenade, J.; et al. Feasibility and Physiological Relevance of Designing Highly Potent Aminopeptidase-Sparing Leukotriene A4 Hydrolase Inhibitors. Sci Rep 2017, 7 (1), 1-19. https://doi.org/10.1038/s41598-017-13490-1.

(17) Werz, O.; Gerstmeier, J.; Libreros, S.; De la Rosa, X.; Werner, M.; Norris, P. C.; Chiang, N.; Serhan, C. N. Human Macrophages Differentially Produce Specific Resolvin or Leukotriene Signals That Depend on Bacterial Pathogenicity. Nat Commun 2018, 9 (1), 59. https://doi.org/10.1038/s41467-017-02538-5.

(18) Werner, M.; Jordan, P. M.; Romp, E.; Czapka, A.; Rao, Z.; Kretzer, C.; Koeberle, A.; Garscha, U.; Pace, S.; Claesson, H.-E.; et al. Targeting Biosynthetic Networks of the Proinflammatory and Proresolving Lipid Metabolome. FASEB J. 2019, 33 (5), 6140-6153. https://doi.org/10.1096/fj.201802509R. 